\title{
Investigating college evolution instruction: Current practices and how they can be improved to overcome student barriers to acceptance
}

Nicholas Adam Wilbur

Follow this and additional works at: https://researchrepository.wvu.edu/etd

\section{Recommended Citation}

Wilbur, Nicholas Adam, "Investigating college evolution instruction: Current practices and how they can be improved to overcome student barriers to acceptance" (2015). Graduate Theses, Dissertations, and Problem Reports. 6949.

https://researchrepository.wvu.edu/etd/6949

This Thesis is protected by copyright and/or related rights. It has been brought to you by the The Research Repository @ WVU with permission from the rights-holder(s). You are free to use this Thesis in any way that is permitted by the copyright and related rights legislation that applies to your use. For other uses you must obtain permission from the rights-holder(s) directly, unless additional rights are indicated by a Creative Commons license in the record and/ or on the work itself. This Thesis has been accepted for inclusion in WVU Graduate Theses, Dissertations, and Problem Reports collection by an authorized administrator of The Research Repository @ WVU. For more information, please contact researchrepository@mail.wvu.edu. 
Investigating college evolution instruction: current practices and how they can be improved to overcome student barriers to acceptance

\author{
Nicholas Adam Wilbur \\ Thesis submitted \\ to the Eberly College of Arts and Sciences \\ at West Virginia University
}

in partial fulfillment of the requirements for the degree

Master of Science in

Biology

Michelle Withers, Ph.D., Chair
Jonathan Cumming, Ph.D.

Katrina Stewart, Ph.D.

Department of Biology

Morgantown, West Virginia

2015

Keywords: Evolution, biology education, evolution acceptance, online learning 


\title{
ABSTRACT \\ Investigating college evolution instruction: current practices and how they can be improved to overcome student barriers to acceptance
}

\author{
Nicholas Wilbur
}

The United States is ranked very low in acceptance of evolution when compared to other countries of similar socioeconomic status. The resistance to evolution extends to high school students and teachers, where much research has been performed on the topic of evolution education and the context is well understood. The initial goal of my thesis research was to establish a context for evolution education at the post-secondary level, which was accomplished by performing a national survey of evolution instructors. Although there was great variation among high school teachers, college instructors were surprisingly consistent in their training, methodology and personal views. The second goal of the study was to develop and investigate the impact of a learning activity that promotes personal reflection on views and beliefs on student acceptance of evolution. On average, students experienced increases in acceptance of evolutionary theory whether they completed the above mentioned activity or a control activity that focused on the evidence for evolution. However the experimental activity resulted in a larger increase in acceptance for students with a lower initial acceptance and students who had higher final acceptance levels experienced higher gains in conceptual learning as evidenced by changes in performance on a pre-/post-concept inventory. Considering the overall uniformity of evolution instruction at the college level, it would be beneficial to further study the influence on student acceptance of evolution of approaches that combine evidence for evolution with confrontation of student belief-based barriers. 


\section{Acknowledgements:}

I would like to thank everyone who contributed to the completion of this thesis. I would like to start by thanking my committee, Dr. Michelle Withers, Dr. Katrina Stewart, and Dr. Jonathan Cumming. My advisor and mentor for this project, Michelle Withers has helped me immeasurably and has influenced my growth as a student and professional in ways that has made my success and the prospects of my future possible. Without her guidance and support, I would not be the researcher, student or the person that I am today. Michelle introduced me to my passion for education and has influenced my development as a professional. The dedication and passion for teaching and mentorship that Michelle has shown towards me as well as all of her students will serve as an inspiration for the rest of my life. Katrina Stewart and Jonathan Cumming have provided invaluable advice and support throughout my graduate career. They have both stood as exceptional role-models in professional achievement, mentoring, and leadership. I am truly appreciative for the influence that these people have had on my life.

I would also like to thank my academic community of graduate peers. Karen Bailey has helped with statistics, planning, revisions, and general planning throughout this project. Micah Waltz has also provided extensive support, advice and revisions throughout my graduate career and on multiple projects. I am immensely grateful for Karen and Micah in the social and professional support they have provided.

Finally, I'd like to thank my family to whom I am eternally grateful. My wife Kristin who has supported me every step of the way has made all of my success possible. Without her to encourage and reinforce me, I would never be where I am today. My parents, Richard and Valerie Wilbur as well as my sister Jessica have been there for me supported me for my entire life. They have helped financially and emotionally, and I could not have succeeded without them. 


\section{Table of Contents}

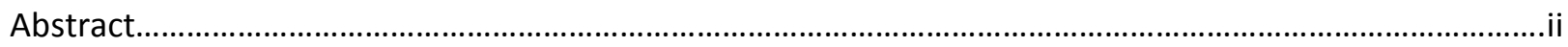

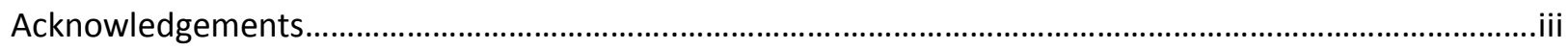

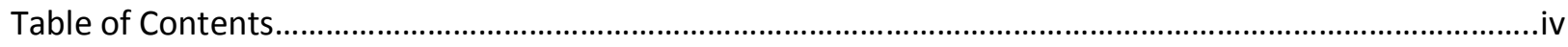

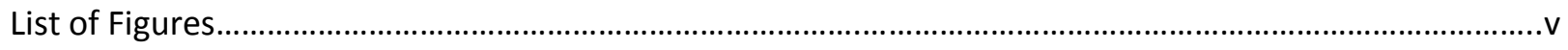

I. Chapter I: Introduction and Literature Review......................................................

II. Chapter II: Teaching practices and views of evolution instructors at post-secondary

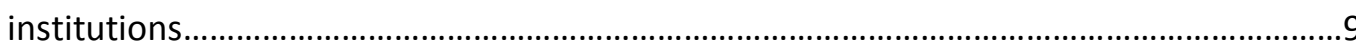

III. Chapter III: Increasing student acceptance of evolution using an online learning activity...

IV. Chapter IV: Discussion and Future Directions......................................................59

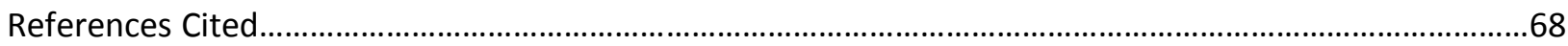

Appendix A: Survey of post-secondary instructors of evolution.........................................................

Appendix B: Experimental evolution learning module ..................................................................

Appendix C: Control evolution learning module...............................................................................80 


\section{List of Figures:}

\section{Chapter 2}

Figure 1 -

Distribution of evolution courses at different class levels.

Figure 2

Distribution of primary instructional methods used.

Figure 3

Distribution of instructional resources used

Figure 4

Page 21

Figure 5

Figure 6

Figure 7

How instructors thought evolution should be taught and how they teach

Pigure 8 -- Personal views of instructors concerning the nature of evolution

Figure 9 Page 27

Instructors views of explanatory power of evolution

\section{Chapter 3}

Figure 1

Average score on post-Concept Inventory based on instructor experience

Figure 2

Distribution of pre and post-MATE scores

Figure 3

Change in student perception based on completion of an online evolution module

Figure 4

Distribution of students who increased in acceptance by pre-MATE score

Figure 5 Page 48

Acceptance change in students for experiment and control groups

Figure 6

Average acceptance gains per student for those increasing in acceptance separated by pre-MATE score

Figure 7

Normalized Acceptance Gains based on disagreement with evolution on the Pre-MATE

Figure 8

Relationship between level of acceptance and gains in conceptual understanding

Figure 9A

Average pre- and post-MATE scores for students based on their responses to module query

Figure 9B

Average MATE scores for students based on their responses to module query

Figure 10

Average MATE scores for students grouped based on their personal views of evolution 
Chapter I: Introduction 


\section{Introduction:}

Evolution by natural selection is the unifying theory for the biological sciences. Despite, its scientific importance and overwhelming amount of supporting scienctific evidence, American society struggles with acceptance of evolution as a valid theory. In the 1920's many Americans perceived the post Great War society as immoral and, as a result, religious fundamentalism became increasingly popular (Moore, 2001). With the increasingly popular views of fundamentalism came political movements such as prohibition. Following the success of the prohibition effort, fundamentalists' sights soon turned toward education reform and focused most notably on the perceived evil influences of evolution. Multiple states passed laws similar to Tennessee's Butler Law, making it illegal "to teach any theory that denies the story of the Divine Creation of man as taught in the Bible, and to teach instead that man has descended from a lower order of animals." John Scopes was convicted for violation of Tennessee's Butler Law in 1925 and although the ruling was later overturned, school boards throughout the United States became even more disinclined to address evolution. By 1929, the fear of backlash all but completely removed mention of evolution from high school textbooks. It wasn't until the 1940's that tentative reintroduction of evolution into high school biology textbooks began. Many school boards are still reluctant to include evolution in their curriculum. Currently, multiple states have standards requiring that science students "critically analyze key aspects of evolutionary theory (Branch \& Scott, 2009)."

Although evolution has slowly increased in prominence in textbooks over the past few decades, many Americans are still greatly influenced by the persistent impacts of the fundamentalist movement. A survey of 32 countries in Europe, plus Japan and the U.S., found that only about $40 \%$ of Americans accept evolution, placing the U.S. second to last on the list (Miller, Scott \& Okamoto, 2006). The lack of public support for evolution interferes with implementation and effectiveness of educational practices (Brem, Ranney \& Schindle, 2003), increasing the risk of leaving a considerable portion of the public, 
including voters and policy makers, ignorant about the role of natural selection in important public health and ecological issues for our society (Gregory, 2009 \& Nelson, 2008). For example, not understanding natural selection can contribute to development of antibiotic resistant pathogens as doctors overprescribe antibiotics and patients fail to follow their prescribed use (Grant, 2009). Likewise, an evolutionarily illiterate public would have trouble understanding the extinction risks for organisms affected by climate change and other forms of human impact (Gregory, 2009).

Religious beliefs may negatively influence learning and accepting evolution (Köse, 2010) leading to misconceptions and ignorance about basic evolutionary principles that further increase resistance to acceptance creating a self-reinforcing cycle. Given that the Unites States has fallen behind so many other countries in science literacy, particularly regarding acceptance of evolutionary theory (AAAS, Benchmarks for Scientific Literacy), concerns about what is happening in our classrooms and how we can break this cycle and improve evolution education and communication have been rising.

Despite overwhelming evidence supporting the theory of evolution, many states allow alternatives to evolution to be taught in public classrooms (Moore, 2001). High school teachers within the United States identify religious beliefs as influencing how they teach their classes (Smith, 2010). However, multiple religions - including an extensive number of Christian denominations - publicly affirm that there is no conflict between their spiritual beliefs and evolutionary science; indeed many individuals form personal syntheses between their beliefs and scientific evidence (Clergy Letter Project). Approximately $7 \%$ of high school biology teachers actively avoid teaching the theory of evolution in their classes, and about 33\% of biology teachers report spending only 3 days or less on evolution (Rutledge \& Mitchell, 2002). Of the same cohort, only $67 \%$ accept the theory of evolution as scientifically valid. Considering that one-third of biology teachers don't readily accept evolution, it is not surprising that evolution education is lacking in many high school classrooms. 
Along with the influences of religious beliefs, the lack of evolution in high school classrooms may also stem from inadequate preparation of biology teachers. Only $31 \%$ of high school biology teachers report having taken a college course devoted to evolution, and only $33 \%$ report having taken a course devoted to the nature of science (Rutledge \& Mitchell, 2002). Over half (51\%) of biology teachers have had less than 40 post-secondary credits in biological sciences and $14 \%$ have had less than 25 credits. High school biology teachers have also been found to be limited in their knowledge of evolution, where an average score on an evolution questionnaire was only 71\% (Rutledge \& Warden, 2000). Because evolution is often ignored or barely covered in high school, and is often taught by instructors with their own misconceptions, it is not surprising that much of the public is misinformed about the topic (Gregory, 2009). Among undergraduates and even senior biology majors, misconceptions are deeply rooted and can impact the acceptance of evolution (Ingram \& Nelson, 2005).

Acceptance of evolution among college students has tended to mirror the overall public and is not significantly different between first-year students and graduating seniors (Rice, Olson \& Colbert, 2010). However, a 2014 Gallup poll found that acceptance of evolution by college graduates was higher than previous years where college graduates were not significantly different from undergraduates or high school graduates. While the data are inconclusive regarding the impact of college graduation on acceptance, people with graduate degrees show a higher acceptance of evolution (approximately 75\%), which could be due to either increased training in critical thinking or to a selection bias in the population who chooses to continue on to graduate or professional school (Gallup, 2006, 2008, 2010, 2012, \& 2014). The public's partial rejection of evolution, especially among those achieving post-secondary degrees, illustrates the need for educational reform concerning evolution at both the high school and college levels.

Data on the impact that post-secondary biology curricula have on acceptance of evolution by majors is lower than what one may expect. Despite having increased exposure to evolution, biology 
majors are only slightly more likely to accept evolution than the rest of the public (Moore \& Cotner, 2009). First-year biology students were not found to significantly increase in acceptance of evolution after having taken coursework in biology and were not statistically different in acceptance from graduating college seniors. Even students enrolled in upper-level evolution courses are only slightly more likely to accept evolution after completing the course (Ingram \& Nelson, 2005). As such, approximately $40-50 \%$ of college graduates with biology degrees do not fully accept evolution (Verhey, 2005), demonstrating a critical need for analysis of and reform in the way this subject is taught.

Although many post-secondary students do not accept evolution, some success has been achieved in influencing acceptance with innovative methods. Improvements in teaching methodology and pedagogy can improve student learning of evolution as well as acceptance. In 2009, Grant found that by revising course content based on interviews with students and student performance on assessments, student learning of evolutionary topics in introductory courses can be significantly improved (Grant, 2009). Researching and directly addressing misconceptions, while integrating evolution as a binding and underlying concept throughout a semester-long introductory biology course increases student acceptance of evolution (Grant, 2009; Silva, 2012). By performing student interviews and analyzing misconceptions from pre-test data, instructors can more effectively confront barriers to learning evolution, thus increasing learning. A common misconception held by introductory biology students is a Lamarckian view of evolution, where for example, a giraffe's neck will lengthen over a lifetime as a result of stretching to reach higher leaves and that longer neck length can then be passed on to the giraffe's offspring. Knowledge of misconceptions revealed by a pre-test can be used by instructors to adjust their curriculum in order to address the conceptual flaws. Traditional methods of instruction often ignore the possibility of incorrect misconceptions and instead focus on teaching the mechanisms of evolution along with scientific evidence for evolution (Silva, 2012). Students enrolled in an upper-level undergraduate evolution course relying on traditional lecture methods experience 
limited increases in acceptance of evolution (Ingram \& Nelson, 2006). Since active, student-centered instruction is not yet a widespread practice in college biology courses and traditional classrooms using evidence-based approaches to teaching evolution are limited in their success, pedagogical reform efforts should help the efforts to improve acceptance of evolution.

While much is known about how high school teachers were trained, what their beliefs are and how those two factors impact how they teach evolution, there is a lack of information about the instructional practices and views of college instructors who teach evolution. As previously mentioned, high school biology teachers often have not taken evolution-based courses and sometimes even avoid teaching evolution in their classrooms, and one-third claim that they either do not accept evolution as valid science or are unsure. Given the state of high-school evolution instruction, as well as the low rate of acceptance among biology majors, it is important to establish a similar understanding of the scope and context of evolution-based instruction at the post-secondary level.

Having established a perspective for evolution education at the post-secondary level, the effect of alternative intervention methods on improving acceptance of evolution needs to be investigated. Low rates of acceptance among biology majors, as well as college students in general, it is apparent that teaching the facts and evidence for evolution is not sufficient. A theistic position is not necessarily contrary to students learning evolutionary concepts (Rice, Olson \& Colbert 2010; Ingram \& Nelson, 2005). However, the ability to simultaneously hold theistic beliefs and accept evolutionary principles is not a view commonly held by the public for whom acceptance of evolution is often associated with decreased spirituality (Brem, Ranney \& Schindle, 2003). Brem et al. also claim that, a high percentage of college students, regardless of attitude towards evolution, perceive that acceptance of evolution can lead to various detrimental effects on society such as increased racism, increased selfishness, decreased sense of purpose, and decreased spirituality. Despite this view from college students, clergy from various denominations find no conflict between evolution and their religious beliefs. In fact, Colburn 
and Henriques (2006) found that $74 \%$ of clergy accept evolution, much higher than acceptance among the general public. Thousands of clergy from various religious groups have endorsed the Clergy Letter Project, which boasts the compatibility of evolution with religious teachings.

Many people have a tendency to retain their beliefs despite evidence to the contrary. This idea of belief perseverance is apparent in people that have been shown to rely more heavily on hypothetical explanations than on data when making specific predictions (Anderson \& Kellam, 1992). Students with misconceptions and theistic barriers to accepting evolution are likely to fall into this group, in which the presentation of evidence for evolution may not affect their view as significantly as hypothetical explanation. Although the findings on belief perseverance are mixed, it is widely accepted that data does not influence all people in the same way. In addition to pointing out supposed flaws in evolution, Creationists commonly use hypothetical explanations, with a fair degree of success, as a method of arguing their point (Pennock, 2003). Following the example of religious leaders that have accepted evolution, and the potential power of hypothetical explanations over the presentation of data, an intervention to perceived conflicts with beliefs, where students are guided towards a personal synthesis between their personal views and scientific evidence may provide a supplemental approach to increasing acceptance of evolution.

The work in this thesis encompasses two main aims: 1) to address the lack of knowledge about the educational practices and personal beliefs of college evolution instructors and 2) to investigate the impact of a learning activity that promotes personal reflection on views and beliefs on student acceptance of evolution.

Chapter one addresses the first aim by investigating the scope of evolution education at the post-secondary level. Since most studies have focused on how evolution is taught in high-school, we designed an online-survey to evaluate the practices and beliefs of instructors in post-secondary evolution courses in the United States. All institutional types surveyed offered evolution-based biology 
courses or courses where evolution was a major topic of study. In contrast to high school evolution courses, there was very little variation among the curricula and personal views of instructors of postsecondary evolution courses. Most courses address similar topics where evidence for evolution, mechanisms of evolution, and mutation are the most commonly taught subjects. The vast majority of instructors accept the theory of evolution by natural selection as a biological explanation of the diversity of life on Earth.

Chapter two addresses the second aim by evaluating the effect of an online-learning module designed to help students reflect upon their own beliefs and the assumptions upon which they are based. Since evidence-based approaches of evolution acceptance intervention have been met with limited success, we sought to implement a non-confrontational approach that led students to think critically about the underlying misconceptions and assumptions that may be influencing their acceptance of evolution. A pre and post survey that measures acceptance of the theory of evolution (MATE) was administered to students immediately before and after they completed a learning activity focusing either on the evidence basis for evolution (control) or on the assumptions underlying religious beliefs that might serve as a barrier for accepting evolution (experiment). Over 700 students from five different sections of the introductory biology course for majors at West Virginia University participated in the study. On average, students experienced increases in acceptance of evolutionary theory whether they completed the experimental or control activities. However, the experimental activity resulted in a larger increase in acceptance for students with a lower initial acceptance and students who had higher final acceptance levels experienced higher gains in conceptual learning as evidenced by changes in performance on a pre-/post-concept inventory. 
Chapter II: Teaching practices and views of evolution instructors at post-secondary institutions 


\section{Abstract:}

Background: The United States is ranked very low in acceptance of evolution among the public as compared to other countries, even though, based on content standards, students should be exposed to evolutionary theory by the time they graduate from secondary school. Many studies have focused on how evolutionary theory is taught at the secondary level and the perspectives of the teachers. However, much less is known about these same issues in higher education. This study used a survey to collect responses from post-secondary instructors in the United States about how evolution is taught and how the individuals teaching the evolution courses perceive the theory and its role in shaping life on earth.

Results: Unlike secondary schools, there was much more consistency between the evolution curricula and attitudes of the instructors toward evolutionary theory at these post-secondary institutions. All types of institutions offer evolution-based courses or courses with evolution as a major topic of discussion at the introductory level, and most 4-year institutions also offer upper level evolution courses. Courses of all institution types address the same core elements of evolution. The vast majority of instructors accept the theory of evolution by natural selection as a biological explanation of the diversity of life on Earth, although a small number still hold sympathetic views towards the teaching of Creationism and Intelligent Design.

Conclusions: Despite having such consistency among post-secondary instructors, college graduates as well as the public remain diverse in their acceptance and understanding of evolutionary principles. Engaging student misconceptions and providing evidence for evolution can have an impact on many students, but there is still a sizable portion of the population that remains resistant. With the limited success that current evolution pedagogy is having on post-secondary students, it is important to 
focus research on improving teaching and advocacy in order to increase the impact that college instruction has on students' acceptance of evolution.

\section{Background:}

Evolution by natural selection is the unifying theory for biology that explains the amazing variety and fundamental connectedness of life on Earth, yet acceptance of evolutionary theory among the public in the United States is very low. A 2006 study found that the U.S. ranked 33rd out of 34 countries surveyed in acceptance of evolution (Miller et al.). A low rate of acceptance of evolution is not unique to the United States. Studies have demonstrated that factors such as, high religiosity, low school-life expectancy, low science literacy, and/or low GDP correlate to a lower acceptance of evolution among the public in other countries (Heddy and Nadelson, 2012). However, when compared with countries that are similar with regard to these factors, the US tends to have lower levels of acceptance (Miller et. al., 2006).

Religious beliefs may negatively influence learning about and acceptance of evolution (Köse, 2010) leading to misconceptions and ignorance of basic evolutionary principles. This ignorance may further increase resistance to acceptance thus creating a self-reinforcing cycle. According to a 2014 Gallup poll, about $42 \%$ of Americans accept a Creationist view of human origins, defined as those claiming that "God created humans in their present form," and only about $19 \%$ accept an explanation of evolution that does not involve divine influence. Nearly twice as many college students accept a creationist explanation of human origins as compared to college graduates (Gallup, 2014). However, previous Gallup polls $(2006,2008,2010$, and 2012) show that college graduates are not consistently different from those with some college. The cause for this difference is unknown, but it does raise the question about what students are encountering in terms of evolution education as they progress through college. 
A 2009 study by Moore and Cotner focusing on biology majors, found that the levels of acceptance by first year majors were not different from non-majors. Biology majors can encounter instruction on evolution throughout their entire degree program while non-science majors are more likely to encounter it only in introductory biology classes that may be used to fulfill general education science requirements. Rice et al. (2010) found that senior biology majors were more likely to accept evolutionary theory than introductory biology students. Whether this is due to selective retention of students with higher acceptance or an effect of their studies is unknown. However, even with the increase in acceptance only $57 \%$ of senior biology majors accept evolution.

There are many misconceptions about evolutionary theory held by college biology students (Alters and Nelson, 2002). These incorrect misconceptions may contribute to resistance to learning basic evolutionary and biological principles leaving a considerable portion of the public, who are voters and policy makers, ignorant about the role of natural selection in important public health and ecological issues for our society (Gregory, 2009). The lack of public support for evolution interferes with implementation and effectiveness of educational practices (Brem, Ranney \& Schindle, 2003), increasing the risk of leaving a considerable portion of the public, including voters and policy makers, ignorant about the role of natural selection in important public health and ecological issues for our society (Gregory, 2009 \& Nelson, 2008)). A public that does not have a working understanding of the world in which they live is at risk of making uninformed decisions that have negative impacts on all.

In order to better understand how to improve undergraduate evolution education, we must first have a clearer vision of the landscape of educational practices in evolution at the post-secondary level. While several studies have investigated evolution education in secondary education, examining teaching methods in addition to the acceptance by instructors, none have examined post-secondary evolution 
instruction on a national level. In 2002, Rutledge and Mitchell found that approximately one third of secondary education biology teachers were unsure about or did not accept evolution and almost two thirds devoted seven-days or less to the teaching of evolution. This study also found that $69 \%$ of highschool teachers had never had a course in evolution, and $67 \%$ had never had a course in the nature of science. Since college biology instructors commonly have advanced degrees in biology or related subdisciplines, we hypothesize that acceptance of evolution by instructors of the subject is more uniform at the college level and evolution instruction is more consistent across institutions. In order to test this hypothesis, we surveyed instructors of evolution at a variety of post-secondary institutions around the country on their teaching practices and personal views concerning evolutionary theory.

\section{Methods:}

Survey Design and Instrument:

We designed a survey to address teaching practices and acceptance of evolutionary theory at post-secondary institutions in the United States (see Appendix A). The survey consisted of 30 questions one adapted from a previous survey (Rice et al., 2010) - in four topic areas (see below) and was targeted at instructors of college courses where evolution was either the only or a primary topic. Before distribution, questions were reviewed by two evolution education researchers; a national advocate of evolution education and a survey design specialist. Participation in any question was voluntary and responses from all participants who indicated that they teach a class where evolution is at least a major topic, were used for analysis. Responses from participants only completing demographics portion of the survey, or less, were not used in reported analyses $(n=42)$. A small number of participants skipped particular sections of questions: 15/523 did not respond to questions concerning information about the course(s) they teach (15), and 16/523 did not 
respond to questions concerning personal views on teaching and evolution (16). Responses that those participants provided in other sections were included in analyses. Respondents who taught more than one course were given the opportunity to answer the course information questions for each course. For responses on course-based items, e.g., the level at which a course is taught freshmen, sophomore, junior, senior - all courses were included in data analysis. However, for questions that pertained to instructor-based practices, e.g. instructional strategy - active learning, lecture or both - only answers about primary courses were used in the analysis to avoid over representation of the teaching practices of any single instructor. Any respondents who accessed the survey and indicated that they did not teach a course with evolution as at least a major topic were directed to an exit page.

The survey collected responses in four topic areas regarding the teaching and acceptance of evolutionary theory by instructors at post-secondary institutions:

1) Institutional demographics: six questions on institution type (using simplified Carnegie Classification designations), religious affiliation and department size.

2) Course information: ten questions on class enrollment, frequency of offerings, course level (freshman-graduate), and course topics.

3) Instructional methods and materials: four questions on primary method[s] of instruction and required resources.

4) Instructor views: nine questions on perceptions of what should be taught in an evolution course and personal acceptance of the theory of evolutionary.

\section{Distribution and Participant Selection:}

The survey was administered using Survey Monkey. One thousand eighty-four post-secondary institutions were randomly selected from the Carnegie Classification of Institutes of Higher Education website which compiles information on the accredited post-secondary institutions in the United States. The proportion of each institutional type, Tribal, Associates, Bachelors, Masters, and Research 
Universities, to which surveys were sent, reflected their national representation. As defined by the Carnegie Foundation:

- Tribal schools are those that belong to American Indian Higher Education Consortium;

- Associate Institutions are those in which the highest awarded degree is an associate degree or bachelor degrees constitute less than $10 \%$ of awarded degrees per year;

- Bachelor Institutions award more than $10 \%$ of their degrees as bachelors and less than 50 masters degrees per year;

- Masters Institutions are those that award at least 50 master degrees and less than 20 doctoral degrees per year; , and

- Research Universities (or Doctorate Granting) are those that award at least 20 doctoral degrees per year.

Surveys were distributed through direct email to instructors of evolution as determined by institutional faculty listings on department websites, if known, and to department heads if not. The cover letter sent to participants and first section on the survey specified inclusion requirements and those that did not meet the requirements were directed to an exit page. Technical and specialty schools were not included due to a common lack of biology courses taught by these institutional types.

\section{Statistical Analysis and Response Reliability:}

Raw data were collected from Survey Monkey and reported as percentages. Chi-square $\left(X^{2}\right)$ tests were performed to compare responses from each institution type. All statistical analyses were performed using JMP (SAS) software.

Post-hoc Long-String index (Meade and Craig, 2011) was calculated on responses to identify "careless responses." The longest string of consecutive responses was 20 (out of 72 items). All strings 
that were longer than five occurred in the section where participants indicated which topics were included in their courses. Having long strings of consecutive similar responses in this section would be entirely appropriate for people teaching classes where they covered some or all of the provided topics at a similar level. In addition to calculating long strings, we analyzed responses to consecutive questions that required reverse responses in order to be logically consistent. For example, if a respondent strongly agreed that "Only evolution should be taught as valid science," they should not also strongly agree that "Only Intelligent Design/Creationism should be taught as valid science." There were no instances of participants providing mutually exclusive responses to these sets of consecutive questions.

\section{Results:}

\section{Response rates}

While much is known about the state of evolution instruction at the secondary level, relatively few studies have investigated how evolution is being taught at the post-secondary level. To reveal the national landscape of teaching practices and views of evolutionary theory at the post-secondary level, an electronic survey was distributed to instructors of evolution at institutions throughout the United States. Institutions ( $n=1084$ ) were randomly selected from the Carnegie Foundation Basic Classification of Accredited Institutions of Higher Education list. Our sample constituted $30 \%$ of the total institutions listed on the website. The ratio of institutional types selected reflected their national representation. The overall response rate of institutions contacted by direct-email was 30\% (324/1084) with the highest response rate occurring for Research Universities (86\%, 73/85), followed by tribal colleges $(44 \%, 4 / 9)$, 4year Bachelors and Masters granting institutions $(28 \%, 123 / 440)$ and Associate schools $(16 \%, 88 / 550)$. In 
order to increase the number of respondents, the survey was also distributed through listservs for several professional societies and organizations related to biology research or education research. Results from the random and non-random distribution methods were analyzed separately and found not to be significantly different $\left(X^{2}, p>0.05\right)$, therefore data were pooled for all respondents $(n=523)$. Response rates for pooled data could not be calculated, however representation of each institutional type was found to be $41 \%$ for Research universities ( $n=216$ ), 32\% for Bachelor and Master institutions ( $n=164), 25 \%$ for 2 -year Associates colleges $(n=131)$, and 2\% Tribal/Other colleges ( $n=12)$. Institutions with religious affiliation were found in each institutional type, except Associate schools, and represent $20 \%$ of the total $(n=107)$.

Non-content aspects of post-secondary evolution courses

At all institutional types, more than half of the courses where evolution is a [the] primary topic are taught at the freshmen (35\%) and sophomore (29\%) levels (All Courses; Figure 1). However, the specific distributions of evolution courses across different class levels are significantly different between institutional types $\left(X^{2}(12, N=781)=128.5, p<0.01\right)$, with the biggest difference at Associate schools. Given their 2-year nature, freshman and sophomore courses represent the vast majority of their evolution courses. The four-year Bachelors and Masters institutions have a slightly more equal distribution of evolution courses across the undergraduate levels while Research institutions and Tribal colleges follow the trend of the whole group which is skewed more toward the first two years with junior (18\%), senior (15\%) and graduate (3\%) level courses making up the remainder. This same trend holds for courses addressing evolution when it is not a primary component. Interestingly, when institutions with a religious affiliation are grouped together, they demonstrated a trend toward slightly more upper level evolution courses. 


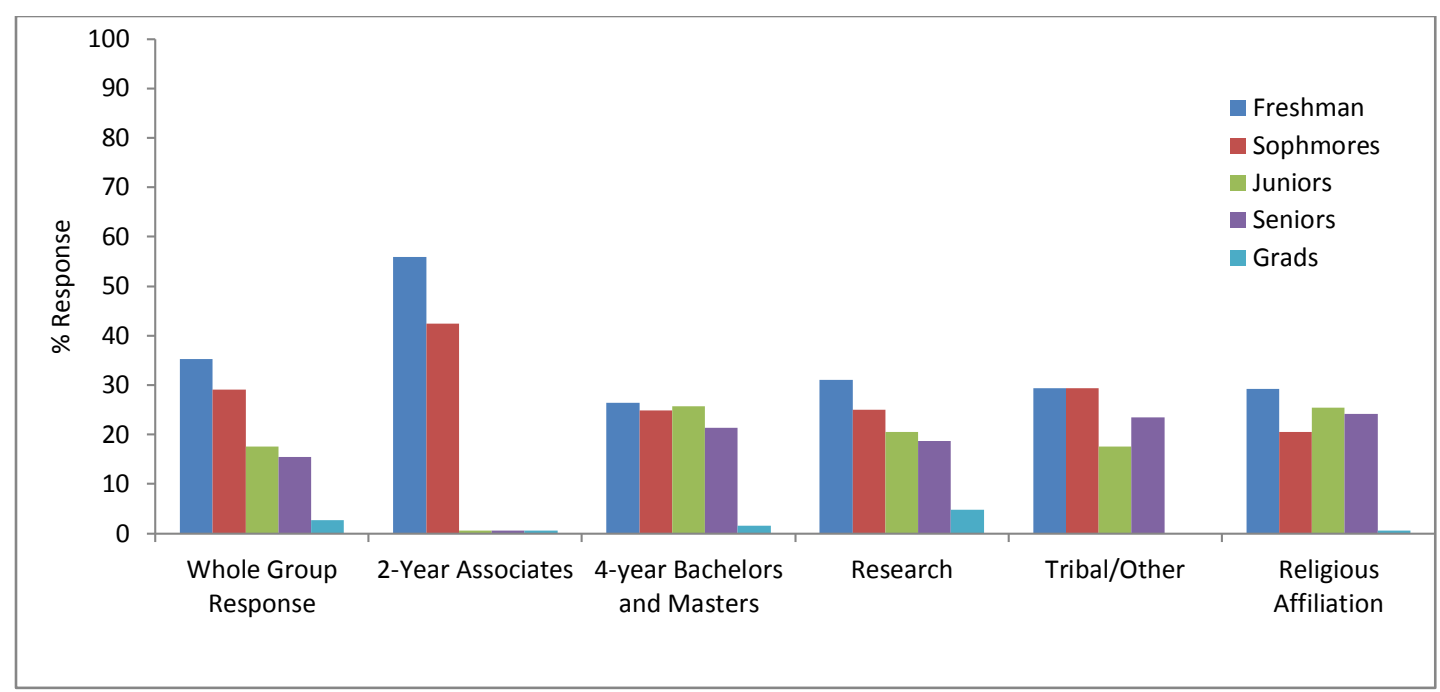

Figure 1. Distribution of evolution courses at different class levels. The frequency distribution for evolution courses at different class levels was significantly different between institutional types (Chi Square, $p<0.01)$.

The majority of respondents, regardless of school type, reported using a mixture of lecture and active learning (66\%), while nearly a quarter use lecture alone (22\%) and only a small percentage use active learning alone (8\%) in their primary survey courses, defined as the course where evolution is the most heavily emphasized (Figure 2). When separated by institution type, there were significant differences in the extent to which instructors relied on the different teaching methods $\left(X^{2}(12\right.$, $N=781)=128.5, p<0.01)$. While the majority still relied on mixed methods, instructors at 2 - and 4-year institutions tended to use lecture alone much more often than active learning alone, while those from research and tribal institutions tended to balance the amount of lecture only and active learning only courses. In terms of the instructional materials used, the textbook is the tool of choice for $91 \%$ of primary survey courses. The use of online resources (64\%) and primary literature (53\%) are also fairly common, with secondary literature being used in a little over a third (36\%) of courses (Figure 3 ). The differences in resource use between institutional types were not significant $\left(X^{2}(12, N=445)=19.53\right.$, $p>0.05)$, however, 2-year institutions tend toward the lowest use of primary literature, while tribal 
colleges lead the pack. Surprisingly, research institutions fall in the lower to middle range for use of primary literature.

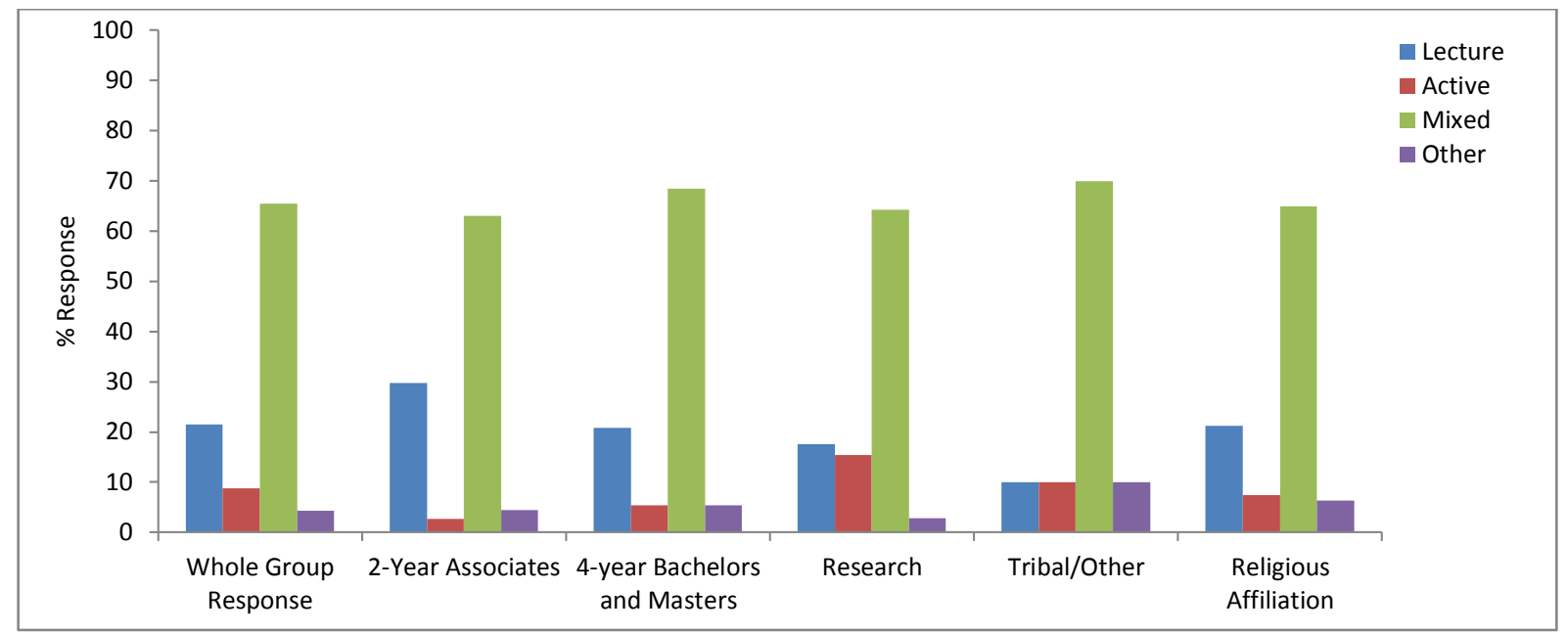

Figure 2. Distribution of primary instructional methods used. The frequency distribution for different methods of instruction was significantly different between institution types (Chi Square, $p<0.01$ ).

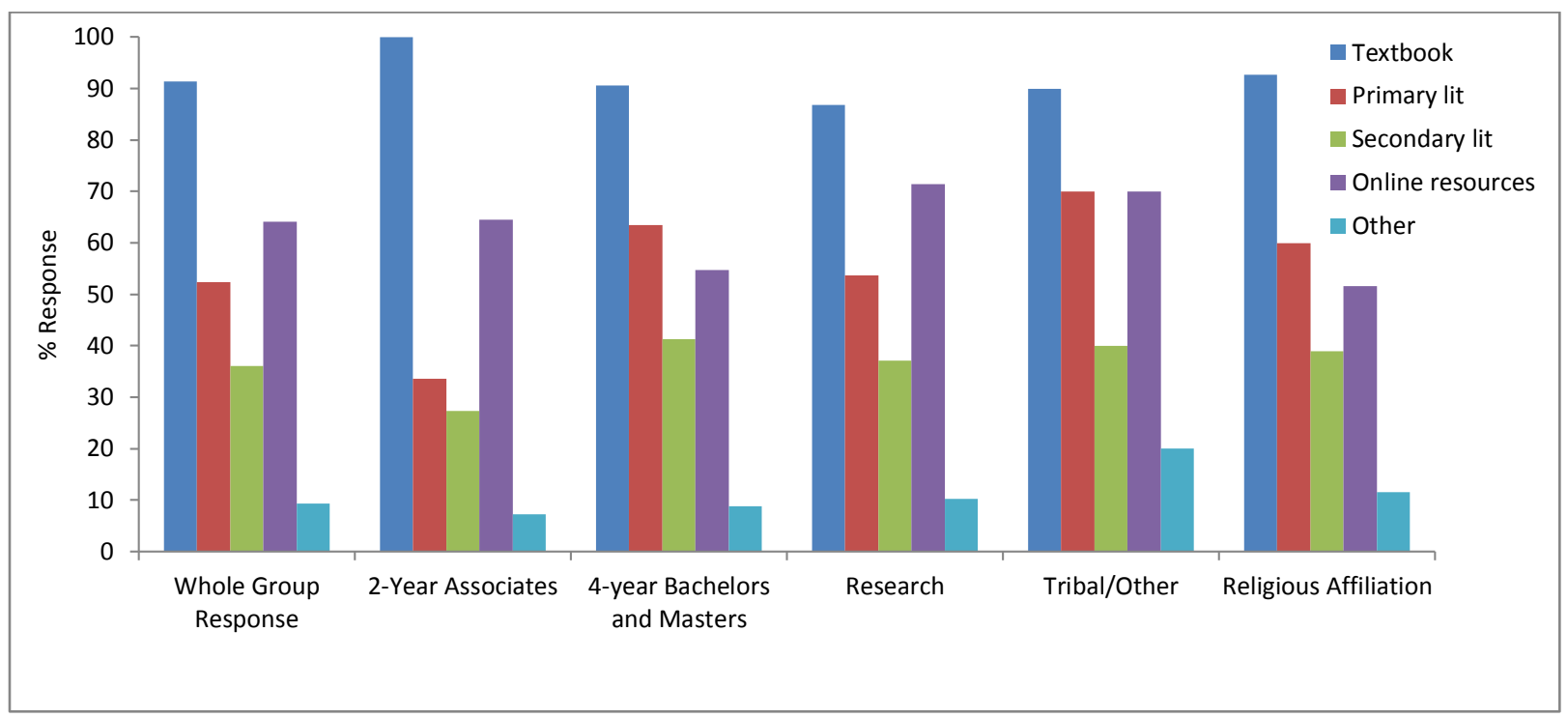

Figure 3. Distribution of instructional resources used. The frequency distribution of instructional resources was not significantly different between institution types (Chi Square $p>0.05$ ).

Course content in post-secondary evolution education 
In courses where evolution is at least a primary component, if not the sole topic, respondents report covering a wide range of aspects of evolutionary theory (3-way Chi Square used to compare all courses; Not Addressed $X^{2}(57, N=438)=49.1$; Addressed Superficially $X^{2}(57, N=438)=40.52$; Addressed Significantly $X^{2}(57, N=438)=21.66, p>0.05$; Figure 4). Of the twenty sub-topics of evolution that we queried, at least $40 \%$ of respondents reported giving all topics significant coverage in their course and at least $75 \%$ gave significant coverage to six of the sub-topics. These six most commonly taught topics include Mechanisms of Natural Selection, Mutations and Sources of Variation, Adaptation, Lines of Evidence for Evolution, Genetics, and Speciation. The three least commonly taught subtopics were The life of Charles Darwin, Rates of Evolution, and History of Life on Earth.

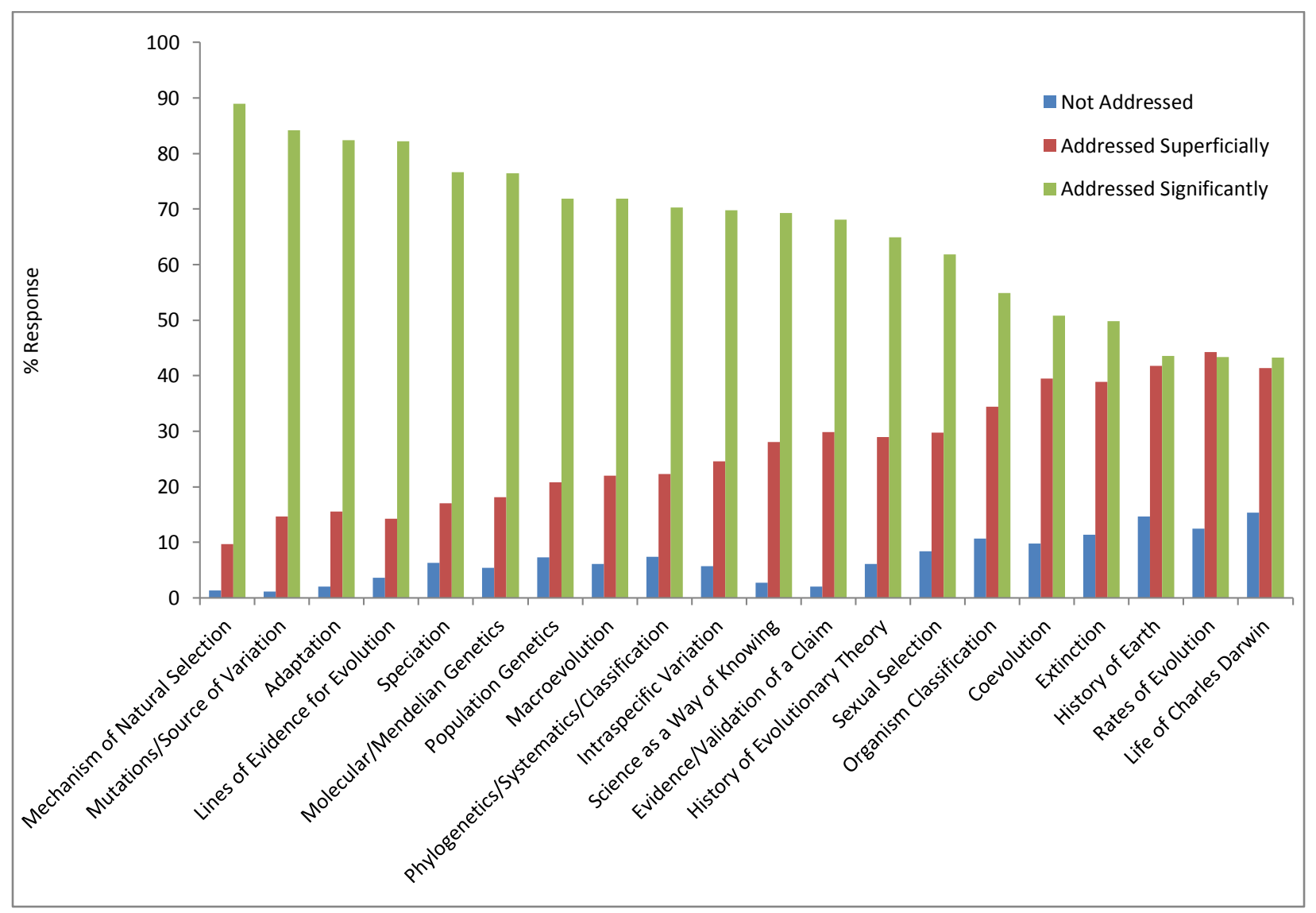

Figure 4. Frequency of topics taught in evolution-based courses. The frequency distribution of topics taught was not significantly different between institution types (comparison not shown) (Chi Square, $\mathrm{p}>0.05)$. 
When asked whether their institutions had official regulations about the teaching of alternatives to evolutionary theory, the vast majority of respondents (84\%) report having no institutional directive concerning the inclusion or exclusion of Creationism or Intelligent Design in their evolution courses; however a small fraction (2\%) of instructors reported having an institutional ban to teaching alternatives to evolution (Figure 5). Those answering that they didn't know if their institution had requirements (14\%) were removed from data analysis and there were no significant differences between institution types $\left(X^{2}(9, N=441)=9.87, p>0.05\right)$. While 106 respondents were from institutions with religious affiliations, only a single respondent reported that their institution required the teaching of alternatives to evolutionary theory.

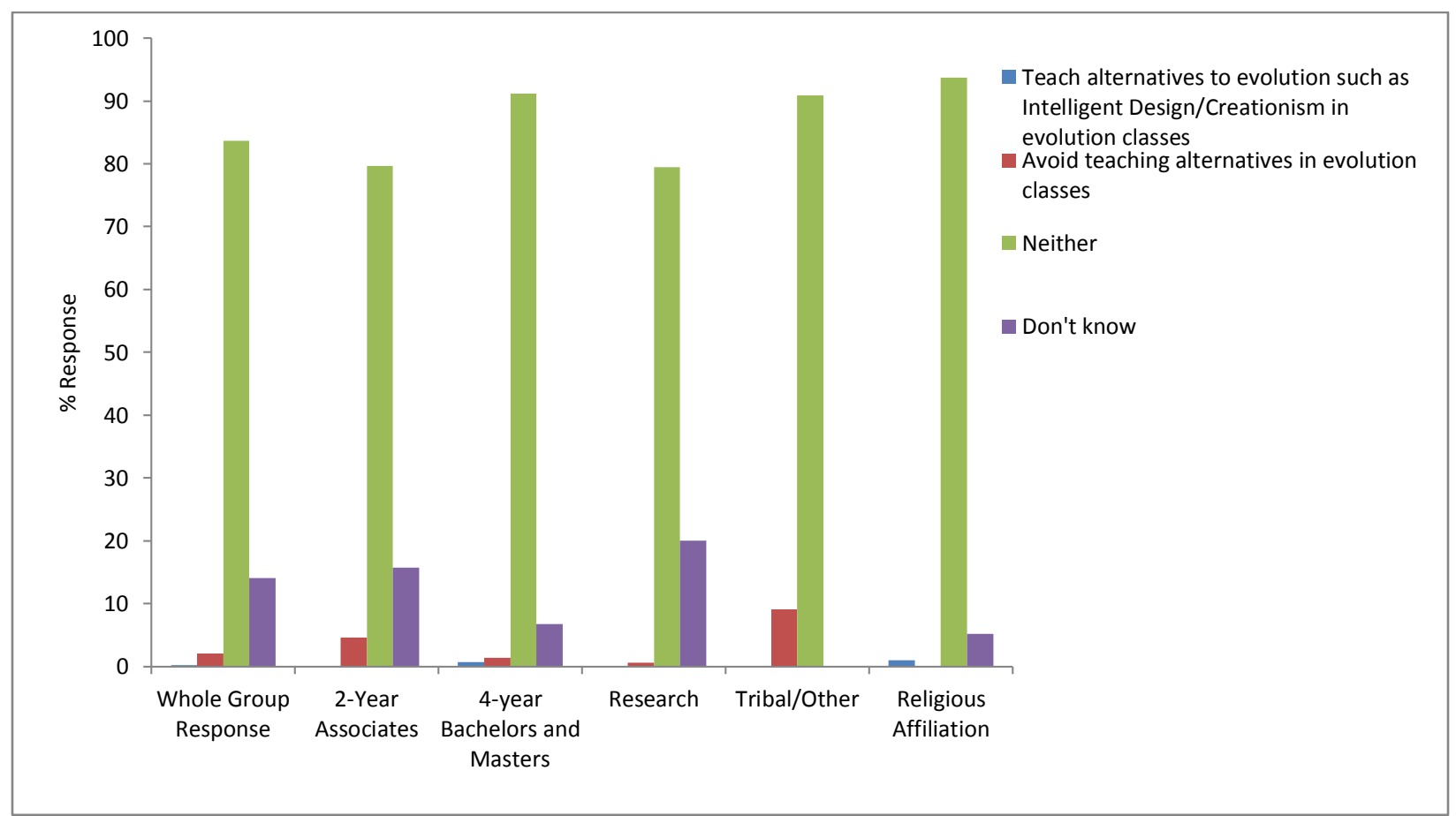

Figure 5. Distribution of institutional requirements on the teaching of evolution and alternatives. The frequency distribution of instructional requirements for the inclusion of evolution and/or alternatives to evolution was not significantly different between institution types (Chi Square p>0.05). 
Instructor Perspectives on Evolutionary Theory

Unlike secondary education, evolution instructors at post-secondary institutions nearly always have post-graduate degrees, with the vast majority of those being doctoral degrees (81\%) (Figure 6). Associate schools have slightly more instructors with Masters' degrees than doctoral degrees while instructors from the remaining institutional types nearly always have Doctoral degrees $\left(X^{2}(12\right.$, $N=479)=199, \mathrm{p}<0.01$ ). Not surprising given the similarity in their level of training, post-secondary evolution instructors are also much more consistent in their personal views of evolutionary theory as compared to secondary teachers. In order to understand how their views aligned with the topics they were teaching, we asked whether or not alternatives to evolution should be or were included in instruction. Nearly $99 \%$ of respondents agreed that biological evolution should be taught in college science classes. Just over half of the respondents (53\%) felt that only biological evolution should be taught in college science classes, while slightly fewer (44\%) felt that addressing why intelligent design/creationism are not scientific could be used to teach nature of science. A very small fraction, 3 respondents from research institutions and 5 from 4-year institutions (1.8\%), felt that both evolution and alternative ideas should be taught as valid science. An equally small proportion, 3 respondents from research institutions and 3 from associate institutions (1.6\%), felt that neither should be taught as valid science. Only a single respondent reported that only Intelligent Design/ Creationism should be taught as valid science (Figure 7A). When separated by institutional type, there were no significant differences in the views of instructors $\left(X^{2}(12, N=173)=11.7, p>0.05\right)$. There was no significant difference between how instructors felt evolution should be taught and how they actually taught it $\left(X^{2}(12, N=172)=9.5, p>0.05\right.$; Figure 7B), but many attributed discrepancies that were present to a lack of available time to discuss unscientific alternatives. 


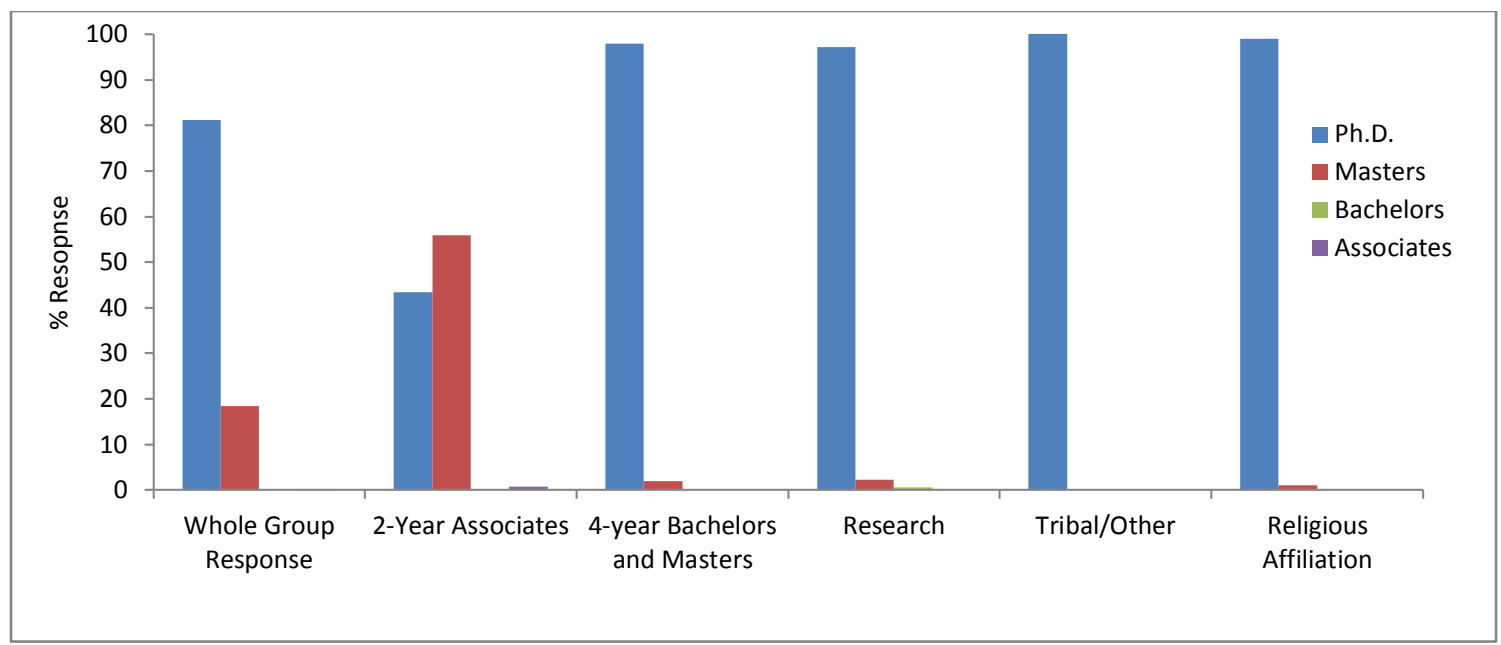

Figure 6. Highest degree earned by instructors. The frequency distribution of highest degree earned by instructors was significantly different between institution types (Chi Square $p<0.01$ ). 


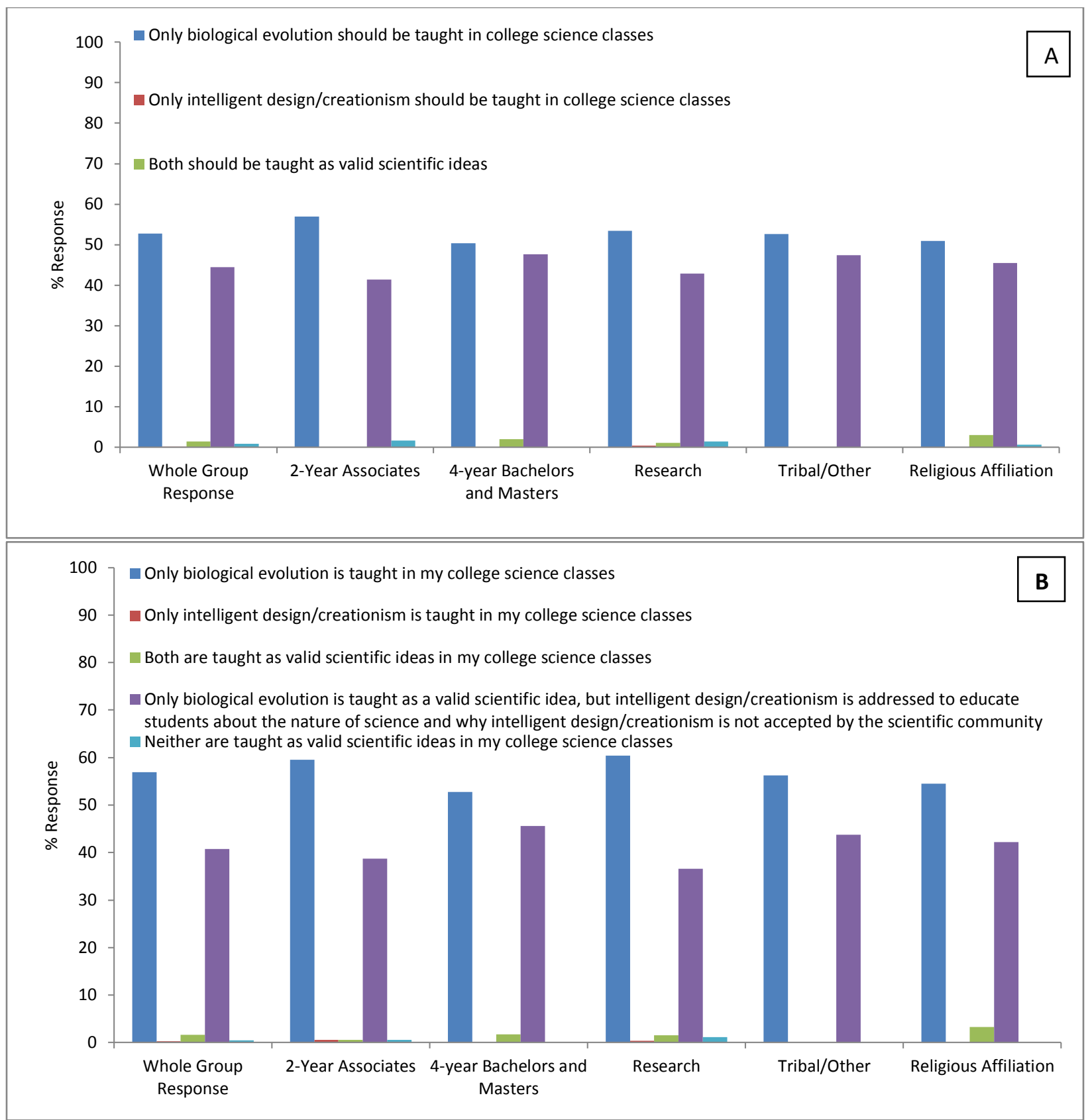

Figure 7 A \& B. How instructors thought evolution should be taught and how they teach. The frequency distribution of how instructors thought evolution should be taught (A) was not significantly different between institution types (Chi Square, $p>0.05$ ). How evolution is taught (B) was also not significantly different between institution types (Chi Square, $p>0.05$ ).

In addition to querying instructors about their perspectives on what should be taught in their evolution courses, we also wanted to determine how their personal beliefs meshed with what the 
theory of evolution tells us about the origin and evolution of life on our planet. In order to gather this information in a quantifiable way, we created a question with several different descriptions of the age of the earth and explanations for the diversity of life from which respondents were asked to select the option that most fit their own beliefs. It was critical, since the options were provided for the respondents rather than allowing for an open-ended response, to have as comprehensive a set of choices as possible. So we looked to other related surveys for models of questions (Rice et al., 2010) and sought input from a senior advisor at the National Academy of Sciences who was involved in the publication of the report, Science, Evolution and Creationism (NAS, 2008). The choices allowed respondents to self-identify as young Earth creationists, old Earth creationists, old Earth evolutionists who believe that evolution occurs with divine intervention, old Earth evolutionists who believe that evolution supports the existence of a deity, old Earth evolutionists who believe that evolution neither supports nor denies the existence of a deity, or old Earth evolutionists who believe that evolution denies the existence of a deity (Figure 8). The responses were not significantly different from different institutional types $\left(X^{2}(15, N=443)=12.42, p>0.05\right)$. The vast majority of respondents (93\%) identified as old earth evolutionists. A large proportion of those ( $83 \%$ of the total) perceive evolution as a natural process that neither supports nor refutes the existence of a God, and nearly equal proportions who believe that evolution refutes (6\%) or supports (4\%) the existence of a God. Only two respondents believe that evolution occurs with God's intervention and only a single respondent identified as a young earth creationist. Two of those three were from institutions with religious affiliations. Respondents were given the option to select a seventh choice if they felt that none of the options represented their views (light blue bars). These respondents (6\%) were asked to supply a description of their perspective. Below are a few representative responses: 
- I agree with the last option but I don't agree that biological evolution supports the idea that God does not exist. Rather, scientific evidence supports that God does not exist, i.e. that supernatural phenomenon do not occur.

- Biological evolution happened on a planet that is now billions of years old and has nothing to do with a God.

- Statement 3 (ancient earth, but God has intervened) and statement 5 (ancient earth, and evolution neither supports nor denies God) I believe are equally close to my perspective and I couldn't pick between them.

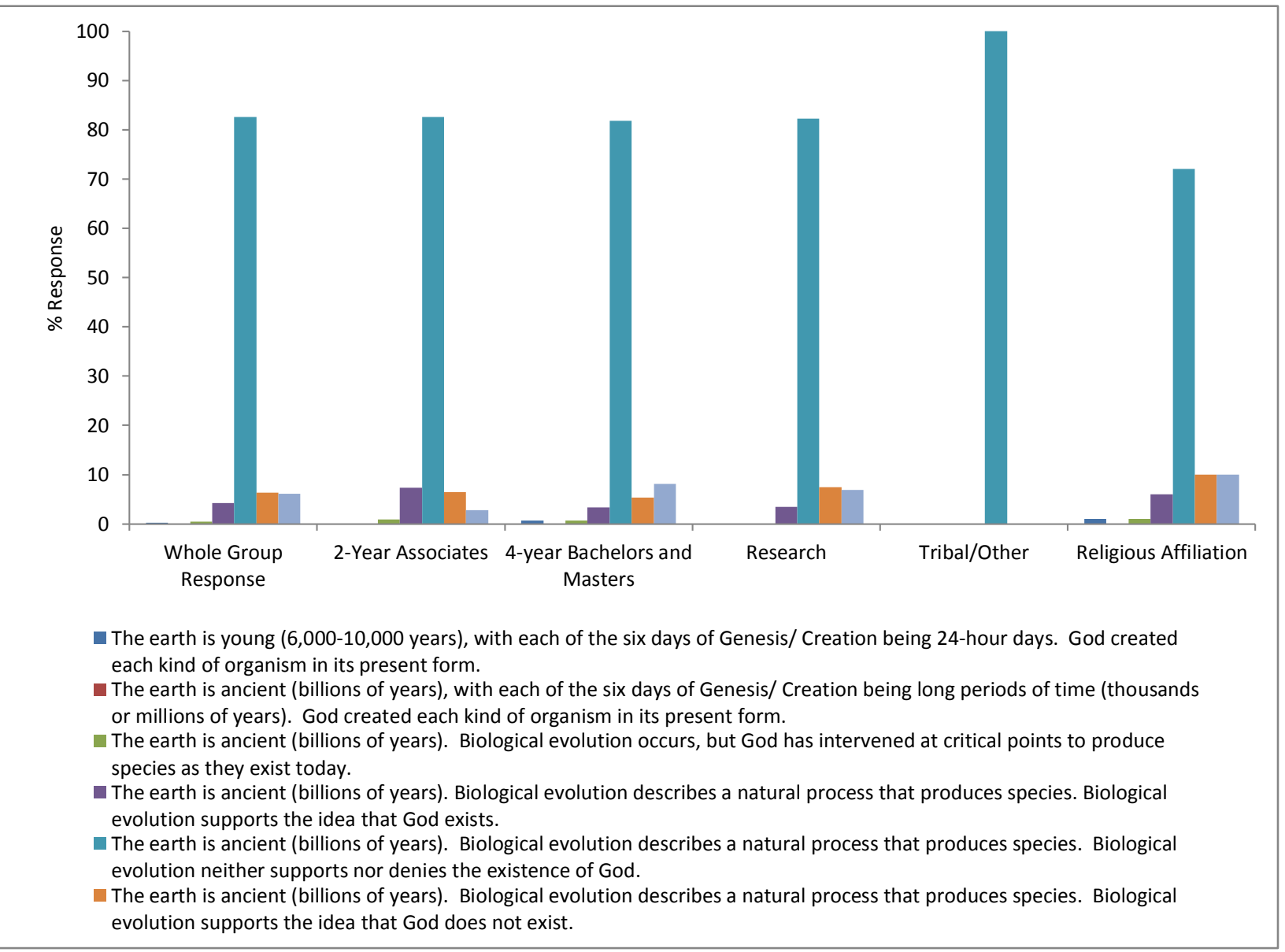

Figure 8. Personal views of instructors concerning the nature of evolution. The frequency distribution of personal views of instructors was not significantly different between institution types (Chi Square, $p>0.05)$. 
The final question on instructor perspectives queried respondents' perspectives on the role of evolution in the origin of life, the origin of humans and the diversity of life forms on earth. Most participants agreed or strongly agreed that the theory of evolution explained the diversity of species (98\%), and the origin of humans (94\%). Surprisingly, a large proportion (66\%) also felt that it explained the origin of life on Earth. Only $25 \%$ of respondents disagreed with this statement. A small proportion of respondents (2\%) disagreed with all three statements. Responses were not significantly different between institutional types (3-way Chi Square comparison made: Disagree $X^{2}(6, N=442)=4.0$; Neutral $X^{2}(6, N=442)=7.5 ;$ Agree $\left.X^{2}(6, N=442)=1.5, p>0.05\right)$. The greatest variation in responses arises from the idea that evolution explains the origin of life on Earth (Figure 9). Research and 2-year institutions had the lowest agreement with that idea while all but Tribal colleges have a slightly lower agreement with evolution explaining the evolution of humans as compared to the diversity of life.

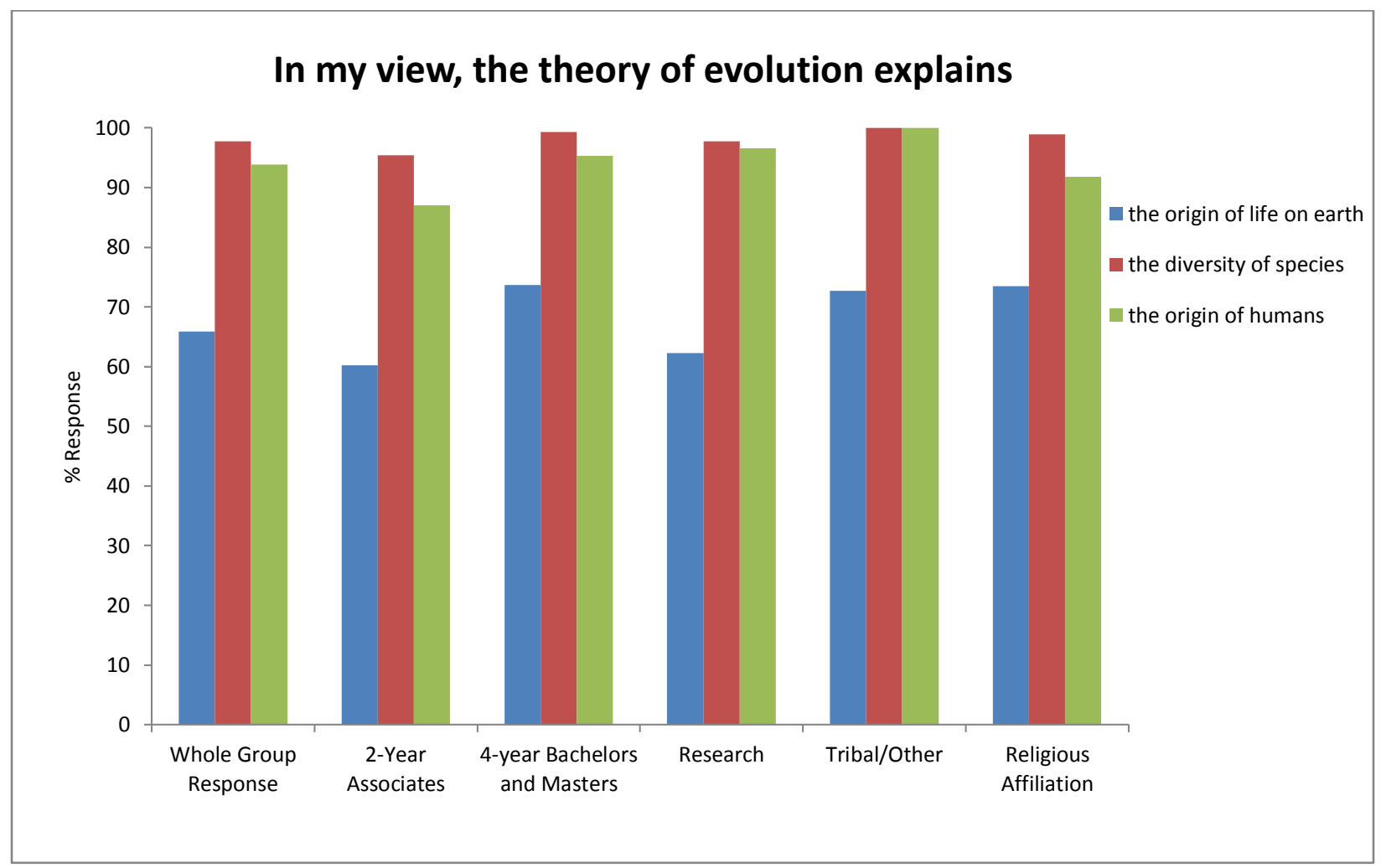

Figure 9: Instructors views of explanatory power of evolution. The frequency distribution of instructors agreement on evolutions' ability to explain the origin of life on earth, origin of humans, and 
diversity of species on earth was not significantly different between institution types (Chi Square, $p>0.05)$.

\section{Discussion:}

In order to understand the influences of student acceptance of evolution, we should first recognize the context in which American students are learning evolution. The purpose of this study has been to elucidate the landscape of teaching practices and instructor perspectives related to postsecondary evolution education. Despite major differences between the practices and perspectives of instructors who teach evolution in secondary education (Rutledge \& Mitchell, 2002), post-secondary evolution instruction is relatively consistent.

We achieved an acceptable overall response rate from our randomized sample (Holbrook et al., 2008). The specific response rates by institution were quite different ranging from an excellent response rate from Research Institutions to a low response rate from 2-year Associate schools. Therefore, our strongest conclusions can be drawn for Research, Tribal and 4-year Bachelors and Masters Institutions. However, given the consistency in responses across all institutional types, the lower response rate from 2-year institutions may still constitute an accurate representation. The possible absence of a Biology Department or classes with at least an emphasis on evolution may have contributed to the lower response rate from 2-year institutions and thus may constitute an acceptable rate of responses from schools with those classes.

Since evolution is a fundamental organizing principle of biology, we were not surprised to find that, regardless of institutional type, half or more of the evolution courses were taught during the first two years of college. Upper level courses are often taught by faculty with specializations in that topic area. Since departments can differ drastically in their faculty representation of different sub-disciplines of biology, we were not surprised to see more variety in the proportion of upper level courses in evolution. At first glance, we did not expect to see such a high proportion of mixed lecture and active 
learning classes given the somewhat preliminary state of biology education reform at most postsecondary institutions. However, upon further reflection, the ambiguity of the label and the broad possible interpretations of the respondent, the mixed label could be applied to a range of courses from primarily lecture with a few open-ended questions to mostly interactive with occasional mini-lectures to set up or reflect upon learning activities. What our data do not demonstrate is the proportion of engagement in the mixed classes. By definition a lecture-only course would have negligible, if any, interaction with students and even though most post-secondary biology faculty probably have not had formal pedagogical training, we would still expect there to be at least some interaction with students in most courses. Given the less ambiguous nature of the active learning only label, we expect that respondents who chose this designation, in fact, were teaching reformed classes using active learning approaches. While we would like to see a much higher representation of that approach, we were pleased to see that, at Research and Tribal institutions, there were at least as many active only as lecture only courses. We expect that on average, class sizes at 2- and 4-year institutions are smaller than those at research institutions; therefore we were somewhat surprised to see that those institutions have a much higher proportion of lecture-only courses compared to active only. For 2-year institutions, this may arise from perceived constraints on content coverage imposed by the institutions into which their students feed.

Textbooks are ubiquitous on college campuses, especially for use in lower level courses, so it is not surprising that they were reported as the primary content resource, regardless of institution type. Given that we were querying science instructors, we were gratified to see that primary literature was employed by more than half of the respondents from most institutions. However, because primary literature is more commonly employed in upper level courses, those could account for much of what is reported here. This might also explain why 2-year associate schools reported less reliance on primary literature because nearly all of their courses are taught at the freshmen and sophomore levels. 
Pedagogical reform efforts in biology promote authentic research experiences and use of primary literature earlier in the undergraduate experience, so we would expect use of primary literature to increase as education reform spreads. Online resources, although the newest form of instructional tool queried, is second only to the textbook in frequency of use by the group as a whole. Accessibility and utility, especially in large enrollment courses, likely account for a large part of the popularity of this resource whose use will probably continue to rise as more and more resources and platforms become available in this format. There was relatively little variation among topics taught in evolution-based courses, with very few topics that were not at least addressed in most courses. The most commonly taught topics address the core mechanisms and evidence for evolution. Open-ended responses revealed that when facing time constraints, instructors prioritize addressing these core concepts over what they considered to be more "historical" or "contextual" topics. Research on the limited effectiveness of using evidence for evolution to convince some evolution skeptics might call into question this prioritization (Ingram and Nelson, 2006; Rice et.al., 2010; Verhey, 2005).

The vast majority of instructors indicated that their institutions have no requirements for teaching either evolution or alternatives to evolution. Despite the lack of oversight, most evolution courses include only evolution as valid science, while the majority of those that include alternatives do so as examples of non-science. We attribute this consistency in the way evolution is taught to the uniform level of training for its instructors. Nearly all respondents indicated holding professional degrees with the majority being doctorates. Another factor that may contribute this consistent picture is a bias in who responded based on the voluntary nature of the survey. Instructors who teach creationism in evolution classes may be less likely to either take the survey or report teaching alternatives to evolution even on a survey where responses were anonymous. This bias might also extend to underrepresentation of the teaching of alternatives at institutions with religious affiliations. Based on our pool of respondents, only a single instructor indicated a requirement for teaching 
alternatives to evolution in their class. While this person was from a school with a religious affiliation, it was not representative of the norm for our respondents. Differences between what respondents thought should be taught and what was taught were often attributed to time constraints, however a few participants indicated a fear that any time spent discussing alternatives may impart undue credence to those topics as valid science.

Uniform training and the selective nature of biological training, likely accounts for the consistency in evolution instructor beliefs and perspectives as well. While nearly $42 \%$ of Americans claim that "God created human beings pretty much in their present form at one time within the last 10,000 years or so (Gallup, 2014)", only a single respondent reported holding creationist views. As stated earlier, selection bias might be causing an underrepresentation of this group because evolution instructors who hold creationist views might be less likely to participate in the survey. Comparing answers to other questions in that same Gallup poll, our instructors are very different in their beliefs compared to the general public. Less than $1 \%$ of our respondents believe that evolution occurs with intervention from a deity compare to $39 \%$ of Americans claimed that "Human beings have developed over millions of years from less advanced forms of life, but God guided this process." The stark contrast between the views of evolution by college evolution educators and the American public highlights the desperate need for better communication between scientists and the public, more effective education strategies and more effective advocacy efforts.

The final question in the survey probed instructors' perspectives on the role of evolution in three different phenomena: origin of life, diversity of life, and origin of humans. Seeing agreement from nearly all respondents that evolution explains the diversity of life is in accord with the fact that the vast majority of respondents self-identified as old earth evolutionists who saw no connection between evolutionary theory and the presence or absence of a god. However, for all but Tribal colleges, a slightly 
smaller percentage of respondents agreed that evolution explained human origins. The discrepancy in the two responses is interesting in that it mirrors, on a much smaller scale, the difference in acceptance by the general public of microevolution versus macroevolution. A subset of the general public has no problem accepting the idea that allele frequencies change from one generation to the next, but still adamantly refuse to accept that evolution can account for the origin of humans. Of the three responses, the fact that nearly two thirds of our respondents agreed that evolution also accounted for the origin of life was perhaps the most puzzling. While the level of agreement was much lower than for the previous two phenomena, we were surprised that there was any agreement given that the origin of life is still an unanswered question and that biological evolution acts on living organisms. We have two possible explanations for these responses. The first, we did not specify "biological" evolution in the question, so it is possible that some respondents extended the definition of evolution to encompass chemical evolution. The second possibility is that there is a misunderstanding by a subset of evolution instructors that biological evolution does account of the origin of life. Instructors who teach introductory courses spend the majority of their time teaching subjects outside of their sub-disciplinary specialty due to the sheer breadth of topics covered in those courses. Coupled with the fact that "history of life on earth" is one of the least commonly taught topics, it is easy to imagine that instructors who know and accept evolutionary theory would have no problem extending that acceptance to an aspect of evolution with which they are not familiar.

Public acceptance of evolution in the United States is at an unsettling level. Although acceptance of evolution tends to be higher among college graduates, it is still low among those with less education. Secondary education biology teachers are varied in their acceptance of evolution and the degree to which they implement evolution in their classes (Rutledge and Mitchell, 2002). However, this is not the case among post-secondary instructors where evolution is a common and widespread topic. Most post-secondary instructors share similar views of evolution as well as what topics should be 
included in evolution-based courses. Despite this, there are an alarming number of students enrolled in and graduating from biology programs with sympathetic views towards Creationism and Intelligent Design (Brem, 2003; Ingram and Nelson, 2006). Engaging student misconceptions and providing evidence for evolution can have an impact on many students, but there is still a sizable portion of the population that remains resistant. With the limited success that current evolution pedagogy is having on post-secondary students (Silva, 2012), it is important to focus research on improving teaching and advocacy in order to increase the impact that college instruction has on students' acceptance of evolution. 
Chapter III: Increasing student acceptance of evolution using an online learning activity 


\section{Abstract:}

Despite its importance to modern biological sciences, American society struggles with acceptance of evolution as a valid theory. Many high school graduates have little or no exposure to scientific evidence for evolution and acceptance is low, even among undergraduate biology majors. When presented with evidence for evolution, many students still retain beliefs in alternative explanations such as Creationism and Intelligent Design. Many attempts to increase acceptance and understanding of evolution have focused on the use of evidence for evolution, however psychological concepts such as belief perseverance and confirmation bias suggest that evidence is not always sufficient to change peoples' minds. Therefore, this study investigated the impact of an online activity that led students to critically examine the assumptions and possible misconceptions that underlay their perceived conflict between evolutionary theory and their own beliefs. Over 700 students from five different sections of a firstsemester introductory biology course for majors participated in the study. On average, students experienced increases in acceptance of evolutionary theory whether they completed the above mentioned activity or a control activity that focused on the evidence basis for evolution. However, the experimental activity resulted in a larger increase in acceptance for students with a lower initial acceptance and students who had higher final acceptance levels experienced higher gains in conceptual learning as evidenced by changes in performance on a pre-/post-concept inventory. Considering the overall uniformity of evolution instruction at the college level, it would be beneficial to study the influence on student acceptance of evolution of approaches that combine evidence for evolution with confrontation of student belief-based barriers. 


\section{Introduction:}

The United States ranks low in the world for acceptance of evolution. A 2006 study that polled 32 European nations plus the US and Japan, found that the level of acceptance of evolution in the US was the second lowest, just ahead of Turkey (Miller, Scott, and Okamoto, 2006). When compared to countries with similar socioeconomic, religious and political landscapes, the US has a drastically lower percentage of the population that accepts evolutionary theory. Often the biggest resistance occurs in response to evidence on human evolution. In 1982, Gallup began asking Americans about their views on the origin and development of humans. Nearly half believed that God created humans in their present form; over a third felt that humans evolved with God's guidance and less than a tenth accepted biological evolution as the driving force of human evolution. These numbers have changed very little in the past three decades (Gallup, 2014).

Public concern over evolution education dates back to the early 1900s when John Scopes was convicted under a Tennessee law banning the teaching of human evolution (Moore, 2001). Throughout the $20^{\text {th }}$ century, the legal battle over the teaching of evolution was waged at both the state and federal levels primarily focusing on high school. Over the past few decades, research on evolution education in American high schools has shed some light on how evolution is taught and why. Among high-school biology teachers, less than a third have had a specific course in evolution and only about a third have had a course in the nature of science (Rutledge and Mitchell, 2002). This inconsistent training coupled with low public support results in little to no coverage of evolutionary theory in high school biology classes (Rutledge and Mitchell, 2002) and a low rate of acceptance (35\%) by high-school students (Woods and Scharmann, 2001).

In 2014, nearly twice as many people without a college degree accepted a creationist explanation of human origins as compared to college graduates (Gallup, 2014), although there was little 
difference between high school graduates and undergraduates. Whether this is caused by exposure to evolutionary theory in college classes or selective filtering of the population by graduation is not clear. Biology majors are more likely to encounter instruction in evolution throughout college while nonscience majors are more likely to briefly encounter it in introductory classes that fulfill general education requirements. Within the Biology major, increased exposure to evolution seems to have some effect. Senior level biology majors were more likely to accept evolutionary theory than introductory biology students, however the success has been limited (Bishop and Anderson, 1990; Ingram and Nelson, 2005, Rice et al., 2010). Although biology majors are typically taught the evidence for evolution, approximately 40-50\% identify with a creationist view (Verhey, 2005; Moore and Cotner, 2009). Even biology students enrolled in an upper-level evolution course were only slightly more likely to accept evolution after taking the course (Ingram and Nelson, 2005). As such, biology majors are about as likely to accept evolution as the rest of the public, despite having increased exposure to the theory.

While exposure to evidence might help students for whom ignorance or lack of information is the primary barrier to understanding and accepting evolution, the psychological concepts of belief perseverance and confirmation bias imply that data does not influence all students (Anderson and Kellam, 1992). According to belief perseverance, for a variety of topics, including evolution, people have a tendency to hold onto their previous views despite new evidence to the contrary (Klayman, 1995). For students who see conflict between their religious beliefs and evolution, confirmation bias would suggest that they would selectively ignore or discredit evidence that supports evolution thereby maintaining their creationist beliefs.

In order to reach students who are not easily influenced by strategies that present evidence for evolution alone, we created an online evolution activity to help students confront their own beliefs, that may serve as barriers to accepting evidence for evolution. We hypothesize that an online module 
designed to help students reflect upon their own beliefs and the assumptions upon which those beliefs are based will reduce resistance to evolution. In order to test this hypothesis, we compared the impact of two modules - one presenting evidence for evolution and the other fostering self-reflection on personal beliefs - on student acceptance of evolution as measured by the Measure of Acceptance of the Theory of Evolution (MATE; Rutledge and Warden, 1999).

\section{Methods:}

Online Module Design:

In order to test the impact of having students reflect upon their own beliefs and belief structures that blocked acceptance of evolution, two online evolution learning modules were designed: a) the experimental module used a scenario and a series of open-ended questions to foster student reflection upon their own beliefs and the assumptions underlying their beliefs that might be barriers to acceptance of evolution; and b) the control module presented facts and evidence relating to evolution followed by a series of questions whose answers required students to use the content provided. Students from each of seven sections of an introductory biology course for majors were randomly assorted into either the experimental or control groups. The modules were administered to students through their Blackboard-based online course management system. Students were familiar with this course management system as they used it to take quizzes and online exams for their introductory biology course. The modules were designed using an activity-building function that allowed for sequential linking of independent parts such that students were required to complete each section in order (i.e., pre-MATE, evolution module, post-MATE). Students who did not complete every section were excluded from the study.

Experimental Module (Appendix B): The experimental module opened with a description of a famous historical example of conflict between science and religion, the resistance of the church to 
heliocentrism. The opening text also included an excerpt from the Clergy Letter project explaining the lack of conflict between major religions and the theory of evolution. Following the text, were openended questions that prompted students to draw comparisons between their own potential conflicts with evolution, particularly human evolution, and those of the Catholic Church with heliocentrism. The questions guided reflection upon their personal beliefs, their perceived conflicts with evolutionary theory and the underlying assumptions of those conflicts.

Control Module (Appendix C): The control module was designed to employ evidence to introduce evolutionary principles to students. The opening text included multiple excerpts from Science, Evolution, and Creationism, published by the National Academy of Science (2008) that provided information and evidence for evolution by natural selection. The opening text was followed by multiple choice questions that required students to use the information provided. They also provided a confirmation that students had completed the reading.

\section{Evaluation Metrics:}

In order to measure students' acceptance of evolution, we used the Measure of Acceptance of the Theory of Evolution (MATE; Rutledge \& Warden, 1999). The MATE is comprised of 20 statements relating to the validity of evolution as science, for which students must signify their level of agreement. Possible scores on the MATE can range from 20-100 with higher scores indicating a greater acceptance of evolutionary theory. Students took the MATE immediately before and after completing their assigned module.

In addition to the MATE, data from the evolution portion of a regular course-wide pre-/postconcept inventory $(\mathrm{Cl})$ were analyzed to compare changes in student understanding of evolutionary concepts between the experimental and control groups. The pre-/post- $\mathrm{Cl}$ is an ongoing part of the course evaluation and is administered each semester during the first week of class for the pre- 
measurement and during finals week for the post-measurement. The four evolution questions on this test come from three published biology concept inventories (Biology Concept Inventory, Garvin-Doxas and Klymkowsky, 2008; Genetics Concept Inventory, Smith et al., 2008; Introductory Molecular and Cell Biology Assessment, Shi et al., 2010).

Course Context and Instructor Background:

Students who took part in this study were enrolled in the first-semester introductory biology course for majors, BIOL 115 Principles of Biology, at West Virginia University during the Fall semester, 2014. The course and connected laboratory introduce students to basic concepts in cellular, molecular and evolutionary biology, and fundamental science process skills. It is part of a 5-course core series required for biology majors and for some related undergraduate science degrees on campus. It can also be used to fulfill a General Education Curriculum requirement for non-science majors. The course serves primarily first-semester freshmen biology, chemistry or life-sciences related majors and has roughly equal numbers of males and females. Students from all seven sections of this course participated in the study. Section enrollments vary from approximately 100-250 students. Five instructors taught the seven sections. The instructors ranged in rank from Lecturer to Associate Professor and four of the five were trained in scientific teaching through the National Academies Summer Institutes, which promotes use of evidence-based strategies such as active learning, ongoing assessment, and inclusive practices. The instructors range in level of implementation of active, student-centered pedagogies. The degree of implementation is related to their years of experience since training at the Summer Institutes, which spans from 2-10 years. In most sections, some amount of active, group learning occurs including use of personal response system (clicker) questions, case studies, discussion and problem solving. BIOL 115 students are concomitantly enrolled in an accompanying laboratory section that uses a combination of guided and open inquiry to teach scientific method and science process skills. 
Data Analysis:

A total of $n=704$ participants completed every item in the study; 344 in the control group and 360 in the experiment group. Any students with missing or incomplete data were removed before analysis. For some analyses, students were broken into "Agreement" and "Disagreement" groups based on the pre-MATE score. Pre-MATE scores of 60 or less were grouped into the Disagreement category, while scores above 60 were placed into the Agreement category.

The MATE scores were calculated based on responses to the 20 items on the inventory. Responses were Likert-scale, ranging from strongly agree to strongly disagree. Scores ranged from 20100 possible points, where higher scores indicated a greater degree of acceptance of evolution. Students who scored 100 on the pre-test MATE survey were removed from data analysis since there was no room for improvement and none of these students decreased in acceptance during the study. Normalized learning gains (NLGs) for the concept inventory and normalized acceptance gains (NAGs) for the MATE were determined using the following formula:

\section{$\frac{\text { Posttest score-Pretest score }}{100-\text { Pretest score }}$ (Knight and Wood, 2005)}

Data were analyzed using JMP (SAS) and Excel. Paired t-tests were used to compare pre- and post-test scores; two-sample t-tests were performed to compare scores for the control and experiment groups. Analysis of Variance (ANOVA) was used to compare performances and correlation coefficients were calculated to compare normalized gains with MATE scores. Kolmogorov-Smirnov tests were also performed to compare non-normal distributions of MATE scores. 


\section{Results:}

American students, even Biology majors, can struggle with accepting evolutionary theory. For some this might be simply a matter of lack of information or understanding while for others it may indicate a conflict, perceived or otherwise, between the tenets of evolution and their personal beliefs. In order to serve the latter group better, we designed an online learning module to help students reflect upon the assumptions underlying their beliefs in a non-confrontational way in hopes that this would reduce their barriers to accepting evolutionary theory. The module required students to read an historical account of the conflict between science and religion over the concept of heliocentrism. The reading highlighted the major assumption that underpinned the conflict at the time, namely that not viewing Earth as the center of the universe conflicted with biblical interpretations and undermined faith in God. The reading was followed by a set of open-ended questions that related modern conflicts with evolution to the historical scenario and asked students to reflect upon the assumptions underlying their own beliefs in that light. A second module that presented facts and evidence for evolution followed by questions that tested conceptual understanding, was designed to serve as a control for time spent reading and thinking about evolution. To determine if these modules affected student acceptance, we deployed them in seven sections of a first-semester Introductory Biology course for majors. The following Biological topics are taught in roughly this order over the course of the semester: Nature of Science, Membrane Transport, Cell Structure and Function, Energy and Metabolism, Cellular Reproduction, Gene Expression and Regulation, Inheritance, and Evolution by Natural Selection. As part of the regular course evaluation, students take a pre-concept inventory $(\mathrm{Cl})$ during the first week of class and a post-Cl during finals week.

The seven sections of Introductory Biology where the modules were offered were taught by five different instructors. Four of the five instructors had training in scientific teaching through the National 
Academies Summer Institutes. Performances by students on the evolution section of the course pre-Cl, administered during the first week of class, were compared to determine if there were differences in students' understanding of evolutionary theory by section. Student scores on these questions were not significantly different between sections $(f(702)=1.0605, p=0.375)$. However, post-Cl scores were significantly higher in classes taught by instructors who had greater experience with scientific teaching (All 5 instructors $f(702)=4.676, p<0.01$; Instructors grouped by experience $t(701)=3.74, p<0.01$ )

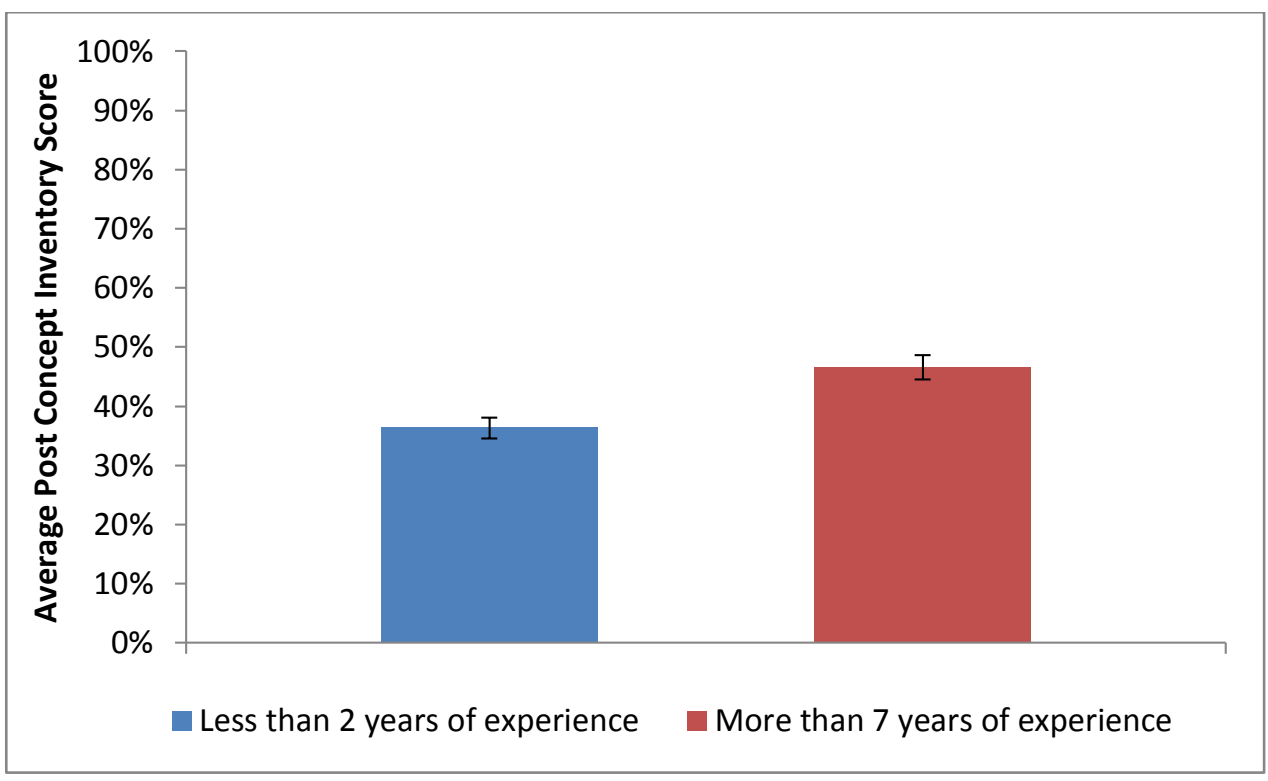

Figure 1. Average score on post-Concept Inventory based on instructor experience. The average student scores on the post-Concept Inventory were significantly higher $(t(701)=3.74, p<0.01)$ in classes taught by instructors who had over 7 years of experience with scientific teaching $(M=46.6 \%, S E=0.021)$ than in classes taught by instructors who had less than 2 years of experience with scientific teaching $(\mathrm{M}=36.3 \%, \mathrm{SE}=0.018)$.

In order to determine if the online modules had an impact on acceptance of evolution, students completed the Measure of Acceptance of the Theory of Evolution Instrument (MATE; Rutledge and Warden, 1999) immediately before and after engaging with either the experimental or control modules to which they were randomly assigned. Although there were no differences in student understanding of evolution by section on the pre-Cl given during the first week of class, there were small but significant differences in pre-MATE scores $(f(702)=2.5087, p=0.041)$ given during week thirteen of the semester just 
prior to beginning the evolution unit for the course. Students in classes taught by instructors who had been practicing scientific teaching for a longer period of time, i.e. more time had elapsed since they attended the National Academies Summer Institute, had significantly higher pre-MATE scores. Despite these differences in pre-MATE scores, there was no significant difference in post-MATE scores across sections $(f(702)=0.5542, p=0.6960)$.

Student performances on the pre and post-MATE were compared to determine if students' levels of acceptance of evolution changed after completing the experimental or control modules. Possible scores on the MATE range from 20-100 points with higher scores indicating a greater degree of acceptance. A score of 60 indicates a neutral stance, neither agreeing nor disagreeing, while scores of 20 or 100 indicate strong disagreement or strong agreement, respectively. The average pre-MATE score for the experimental group was 73.1 and for the control group was 72.7. The post-MATE averages were 75.7 and 74.6 respectively. While the post-MATE scores were significantly higher than the pre-MATE for both groups (experiment $t=5.13, p<0.01$; control $t=6.09, p<0.01$ ), the control and experimental groups were not significantly different from each other (pre-MATE $t=0.484, p>0.05$; post-MATE $t=0.995$, $p>0.05)$. Given that scores on the MATE indicate levels of agreement, we wanted to know if the distribution of students falling into the different levels of agreement were different for the two modules. For both the experimental and control groups, the majority of students ( $80 \%$ And $83 \%$, respectively) scored above 60 putting them at some degree of agreement with evolution before completing the modules (Figure 2). Less than $20 \%$ of students scored at or below 60 before either of the modules placing them in the neutral (experiment $4.1 \%$; control $1.7 \%$ ) to strongly disagree ranges (experiment 15\%; control 15\%). For the experimental group, the percentage of students in all but one of the 10 point increments below 60 went down or stayed the same whereas the changes in the control group were more variable. The number of students at the highest levels of acceptance went up for both groups. 
Although there was an average increase in acceptance for both groups, individual students exhibited all three possible states of change; some increased acceptance, some decreased acceptance and some stayed the same. These numbers were not significantly different between the experiment and control groups: 61\% (control) and 60\% (experimental) increased, 15\% (control) and 18\% (experimental) decreased, and 24\% (control) and 21\% (experimental) stayed the same (Figure 3). Since most students increased in acceptance, we wanted to separate this group from the others to further analyze their distribution patterns. In general, the number of students experiencing increases in acceptance falls roughly into the same distribution for both the control and experimental groups. Of students that increased in acceptance, there was a general trend showing more from lower initial acceptance groups benefitting from the experimental module, and more students from the higher acceptance groups benefitting from the control module, though average pre-MATE scores were not significantly different between groups ( $t=0.365, p>0.05$; figure 4$)$.

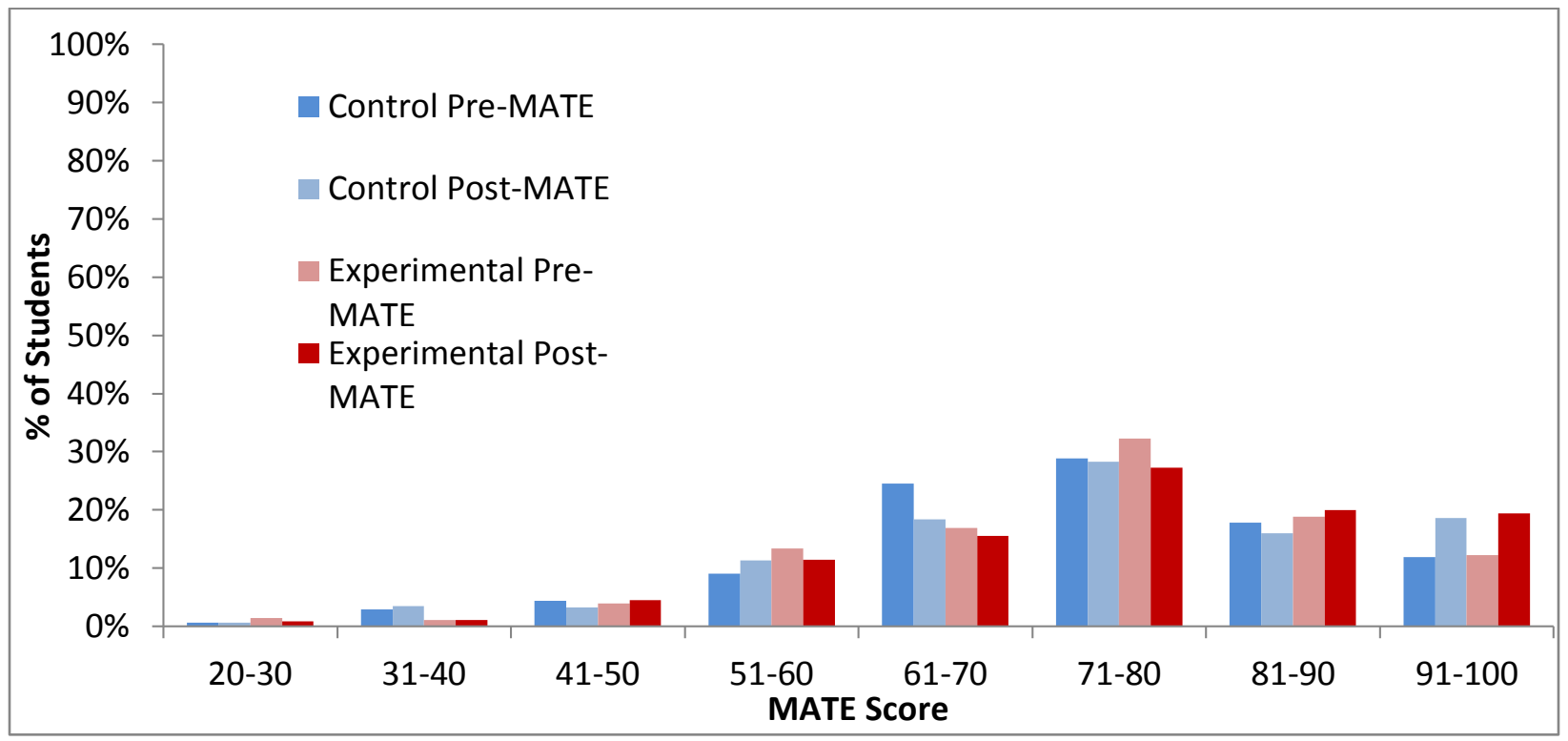

Figure 2. Distribution of pre and post-MATE scores. The distribution of scores on both the pre and postMATE for the control (blue bars) and experimental (red bars) groups. A Kolmogorov-Smirnov test showed that the distributions of scores were not significantly different between control and experimental groups (pre-MATE $d=0.074, p>0.05$; post-MATE $d=0.072, p>0.05$ ). 


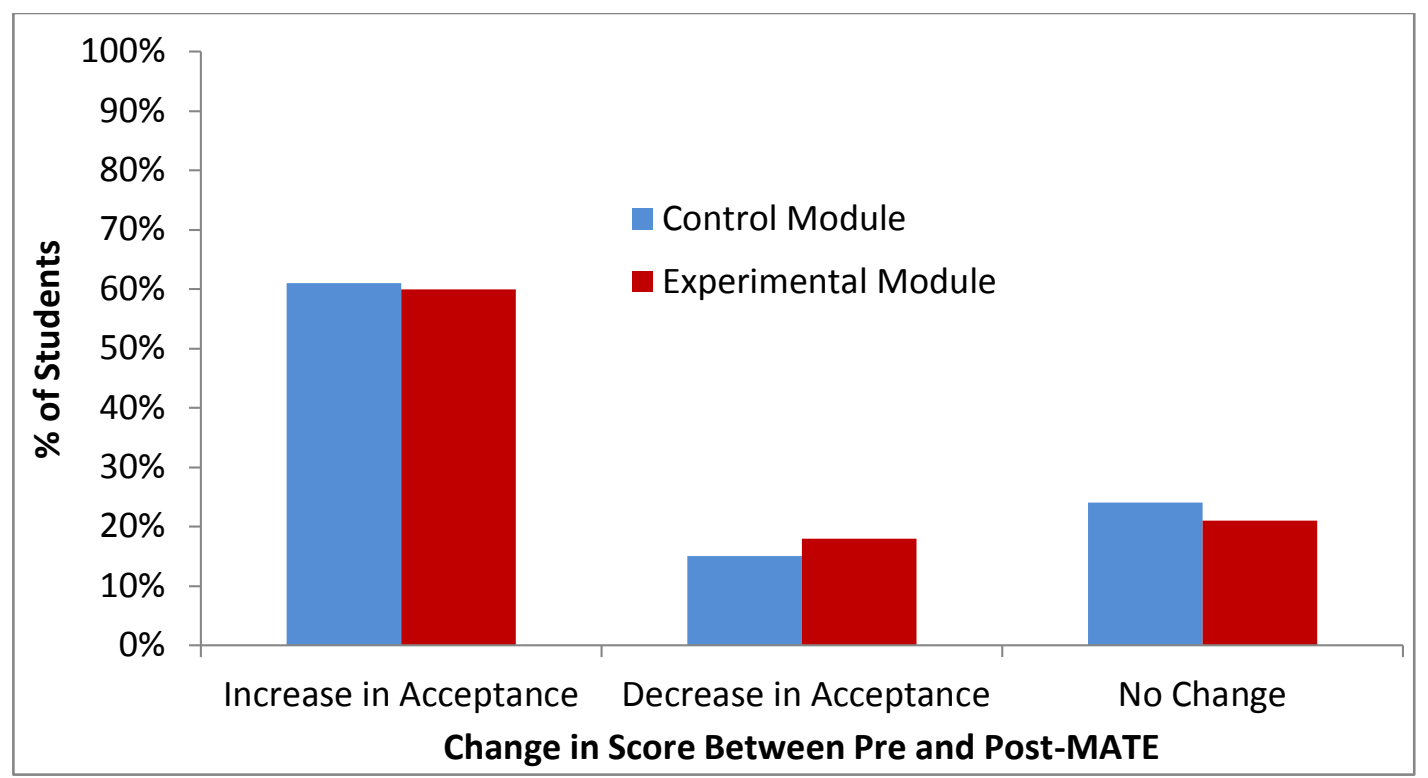

Figure 3. Change in student perception based on completion of an online evolution module. While most students increased in acceptance after completing the modules (control 61\%; experimental 60\%), some students had no change (control 24\%; experimental $21 \%$ ) and some decreased in acceptance (control 15\%; experimental 18\%).

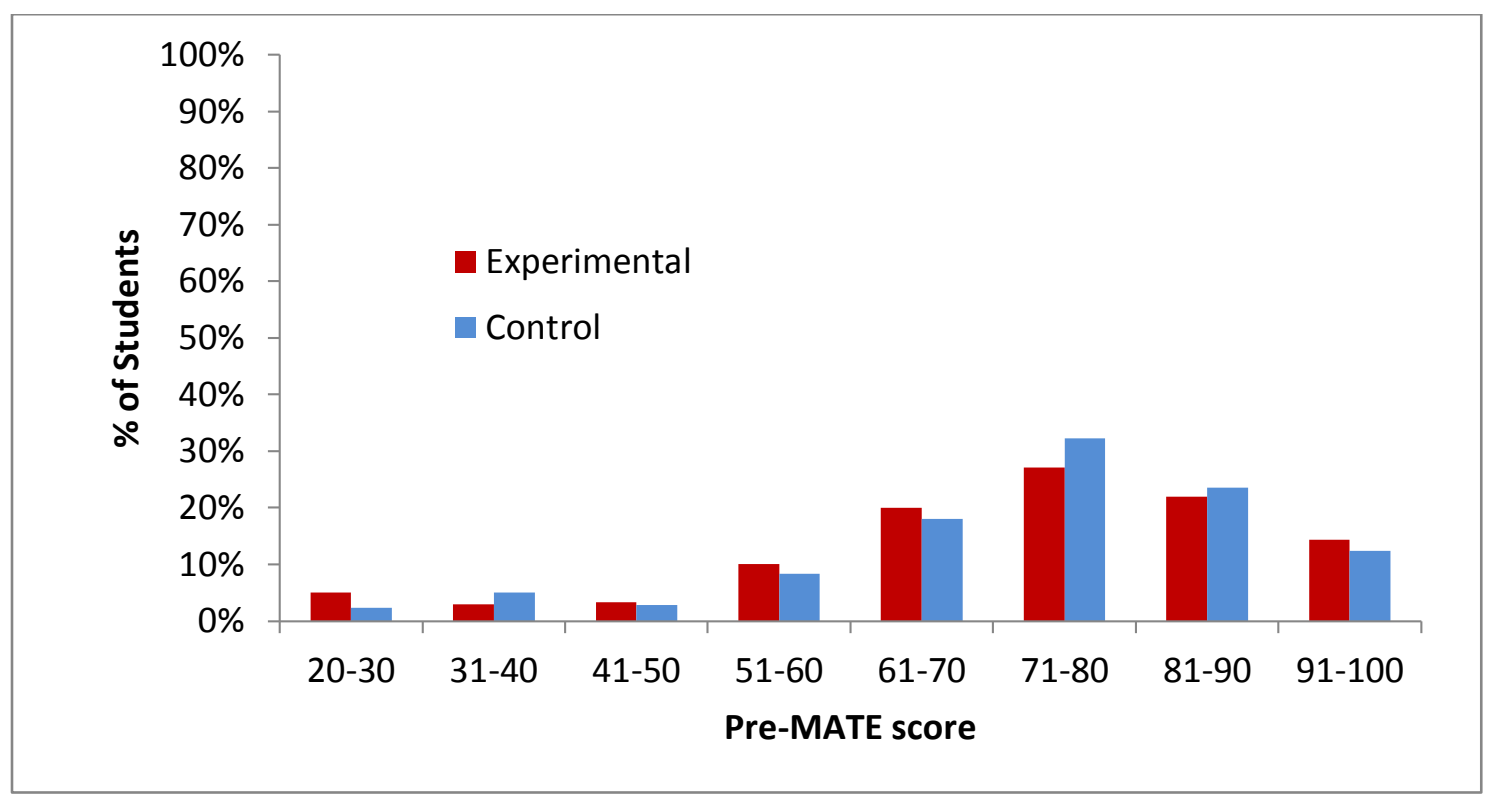

Figure 4. Distribution of students who increased in acceptance by pre-MATE score. Distribution of preMATE scores for students that increased in acceptance after completing the module.

In order to determine the magnitude of the changes in student acceptance of evolution, pre and post-MATE scores were used to calculate normalized acceptance gains (NAGS). Both the experimental 
and control groups averaged positive gains in acceptance ( $11.2 \%$ and $11.0 \%$, respectively) that were not significantly different from each other $(t=-0.25, p=0.80)$. While the average NAGs were not significantly different between the two groups, slightly more students in the experimental group experienced gains of $30 \%$ or higher as compared to the control groups who experienced more gains in the $0-30 \%$ ranges (Figure 5). Both groups had a small number of students who experienced negative gains as indicated previous by the students who experienced declines in acceptance.

Given that both groups had similar numbers of students who experienced an increase in acceptance, but the experimental group tended to have more students with higher gains in acceptance, we were curious to know what the magnitude of gains were for the students who underwent increases in acceptance in both the control and experimental groups. Therefore, we calculated the average acceptance per student grouped by their pre-MATE level of acceptance (Figure 6). Students who completed the experimental module had higher per student acceptance gains in every range of preMATE scores except the two highest, 80-91 and 91-100, with the most drastic differences occurring for students who started with lower initial levels of acceptance. An analysis of how student pre-MATE scores related to their acceptance gains revealed a moderate significant negative correlation for students who initially disagreed with evolution and completed the experimental module $(r(55)=0.444$, $p<0.01)$ but no such relationship for students who completed the control module $((r(51)=0.061, p>0.05)$ (Figure 7). 


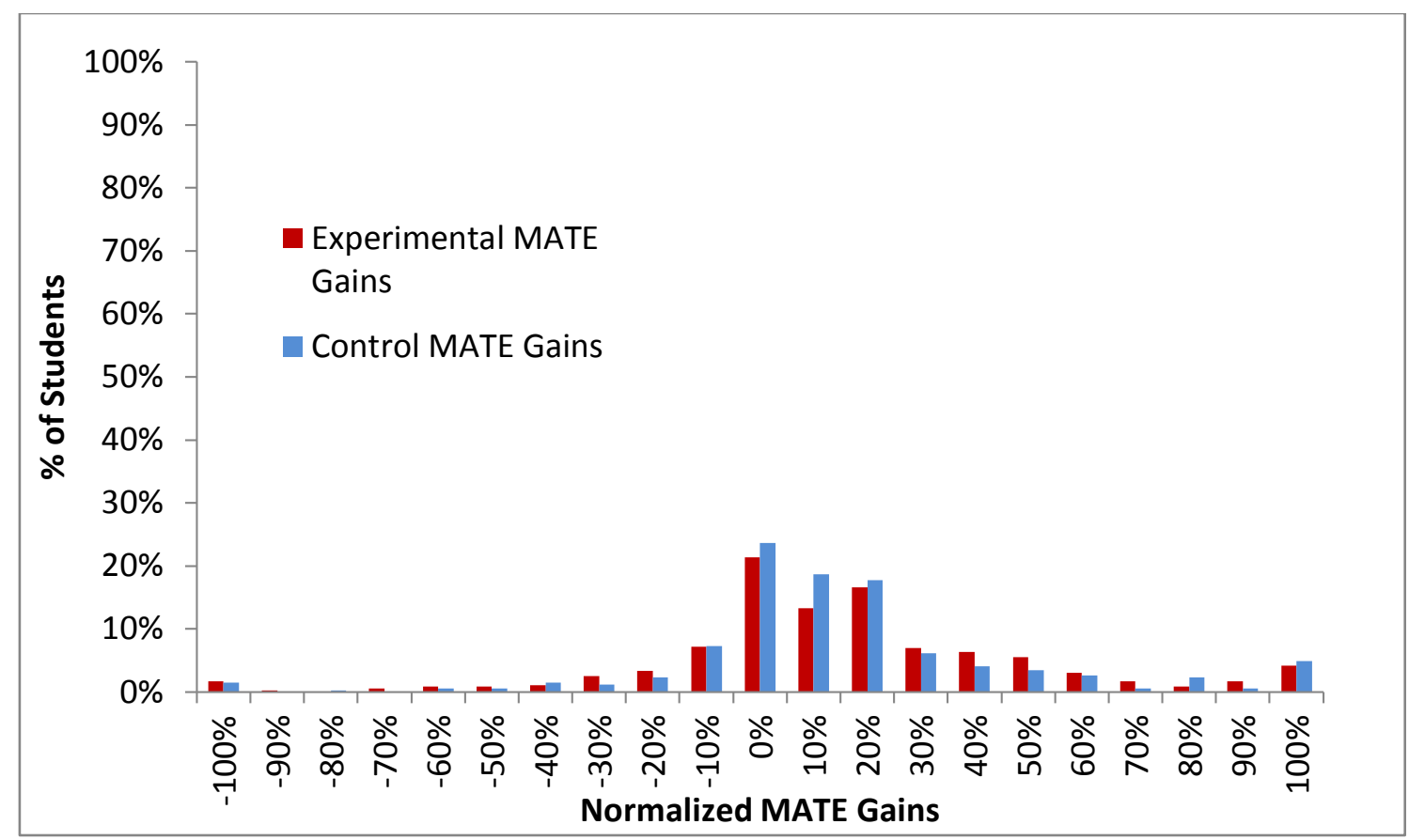

Figure 5. Acceptance change in students for experiment and control groups. The distribution of normalized acceptance gains (NAGS) for students in the experimental group and the control group.

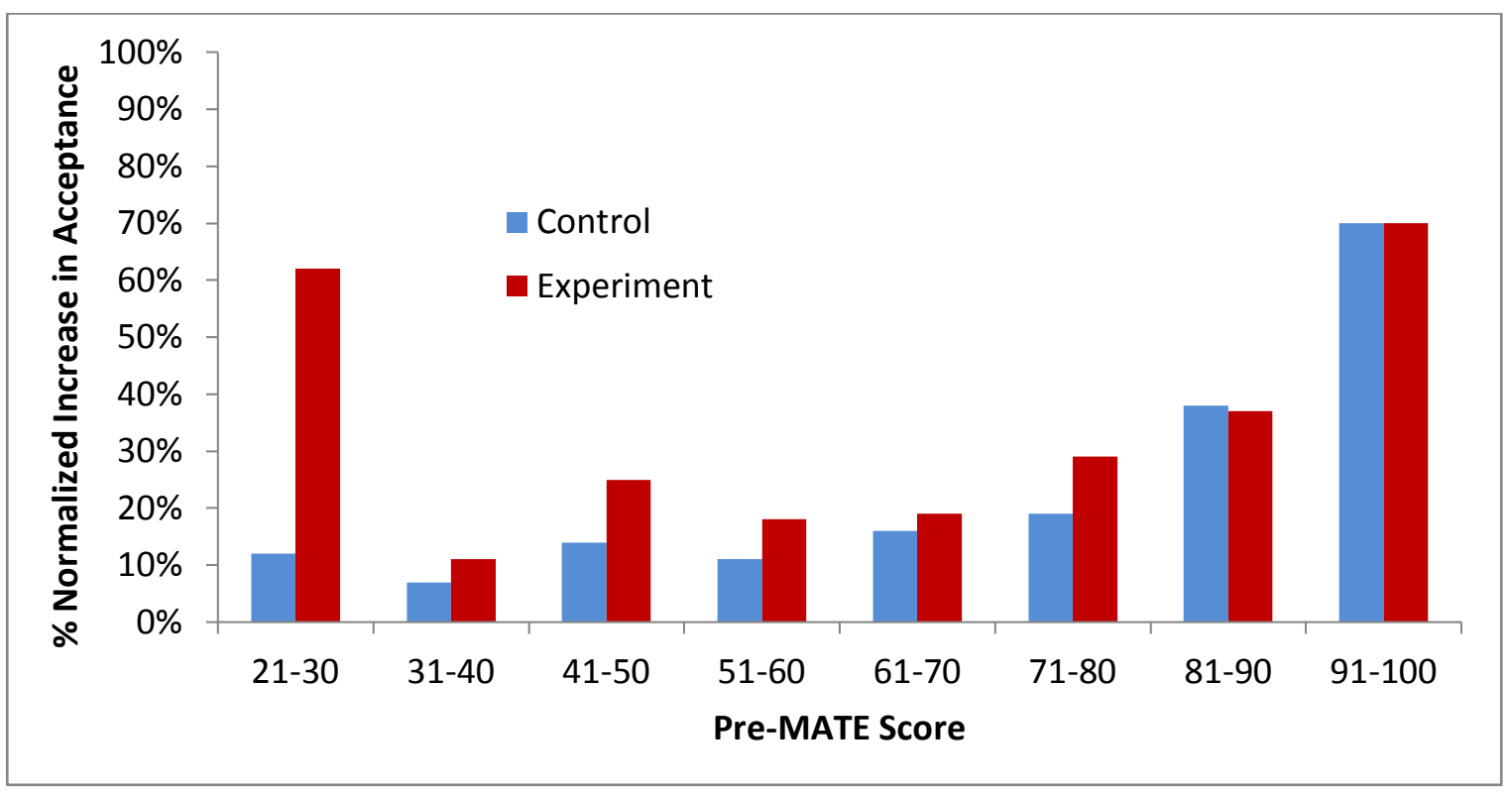

Figure 6. Average acceptance gains per student for those increasing in acceptance separated by preMATE score. Distribution of average per-student normalized gains in acceptance based on pre-MATE score between control and experiment groups. 


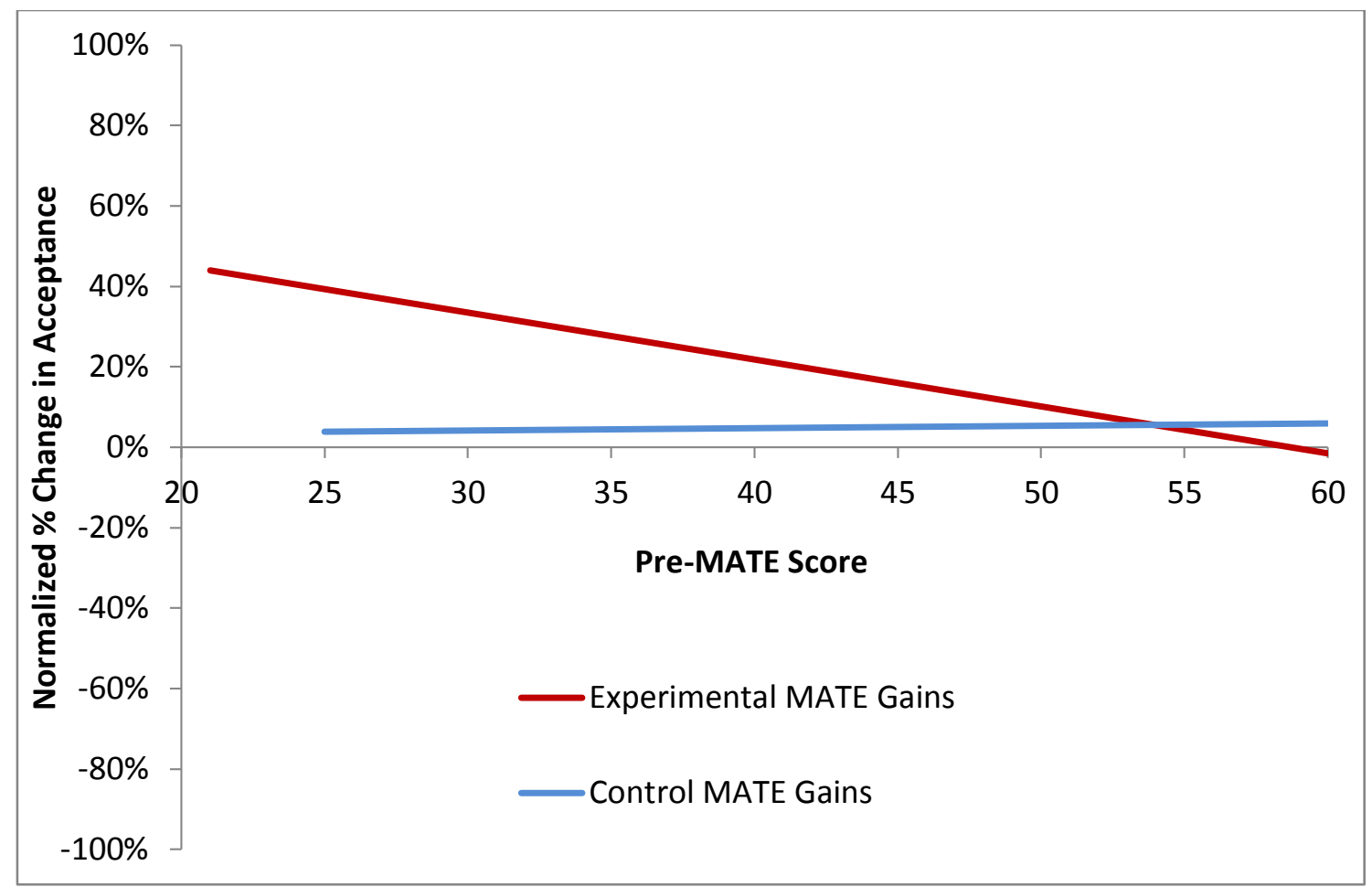

Figure 7. Normalized Acceptance Gains based on disagreement with evolution on the Pre-MATE. There was no significant correlation between pre-MATE score and normalized MATE gains in the control group $(r(51)=0.061, p>0.05)$, but there was a moderate negative relation in the experiment group among students initially disagreeing with evolution $(r(55)=0.444, p<0.01)$.

In order to determine if acceptance of evolution was related to improvements in student conceptual understanding of the theory, post-MATE scores were compared with normalized learning gains on the evolution questions from the course concept inventory. Higher post-MATE scores, which indicate greater acceptance of evolution, showed a significant weak positive correlation with larger learning gains regardless of which module the students completed (control group $(r(341)=0.1699$, $p<0.01$; experimental group $r(359)=0.1276, p=0.015$; Figure 8). Despite this, there was no significant positive correlation between their gains in acceptance (MATE gains) and their gains in conceptual understanding, regardless of which module they completed (control $-r(342)=0.0801, p>0.05$; experimental $-r(359)=0.0221, p>0.05)$. 


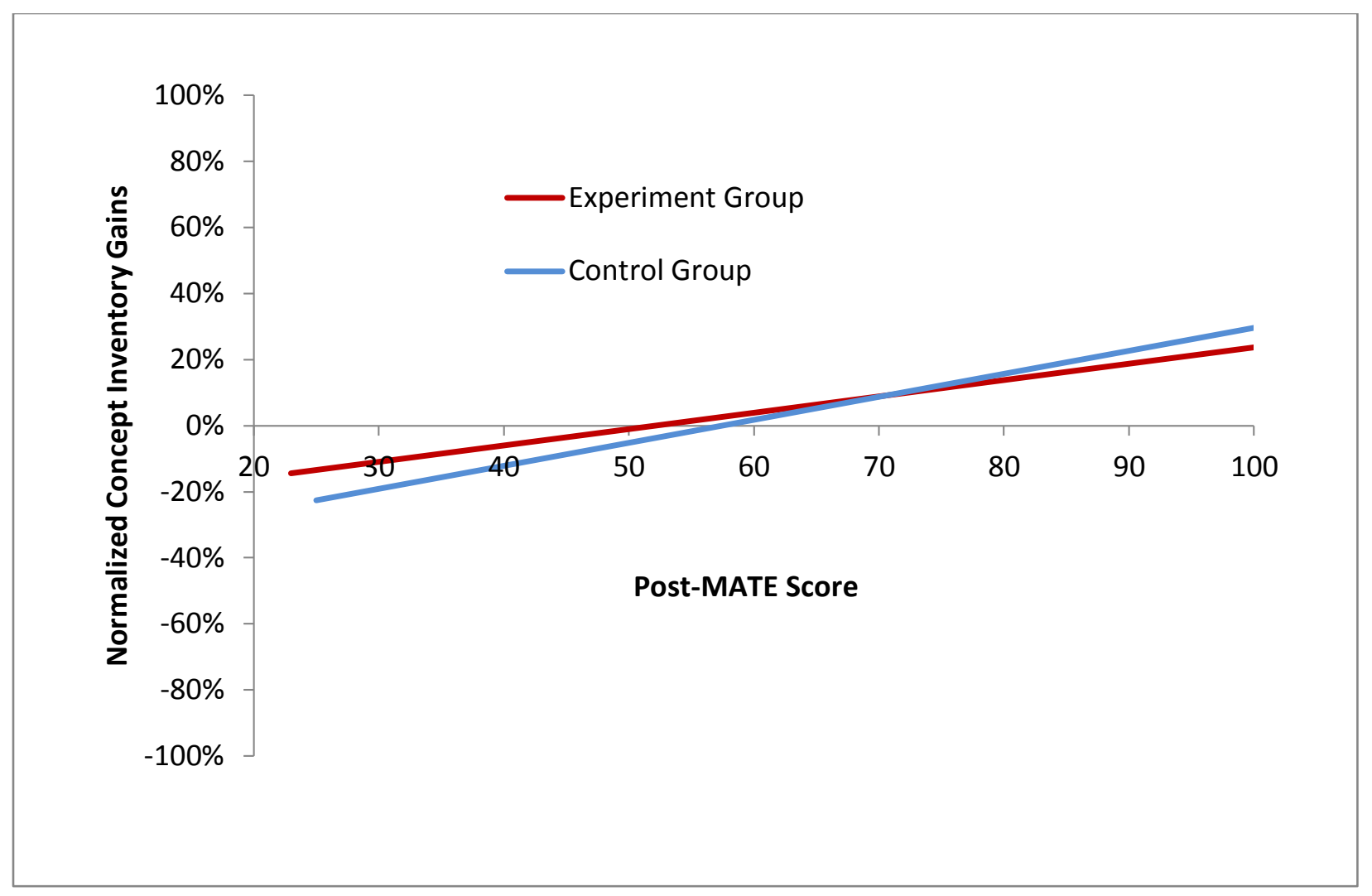

Figure 8. Relationship between level of acceptance and gains in conceptual understanding. There were weak but significant relationships between post-MATE score and normalized learning gains for both the control $(r(341)=0.1699, p<0.01)$ and experiment groups $(r(359)=0.1276, p=0.015)$.

Given that low initial acceptors saw greater increases in acceptance from completing the experimental modules, we were interested in learning how answers to various related to their initial acceptance, final acceptance or changes in acceptance. Some questions led students to consider possibilities that fostered a personal synthesis between religious belief and evolutionary theory in order to reduce the perceived conflict between evolutionary theory and belief in a deity. We were curious as to whether students' ability to entertain these "synthesis" scenarios as possibilities would be indicative of increases in acceptance of evolution. One item on the experimental module posed the following question, "If a supreme deity exists that is responsible for the existence of the universe, could they also be responsible for evolution, resulting in humans descending from an ancestral primate?" There were significant differences between pre- and post-MATE scores based on responses to this query 
$(f(559)=9.40, p<0.01 ;$ Figure 9). Students who answered "Yes" on this question were more likely to score higher on both the pre- and post-MATE.

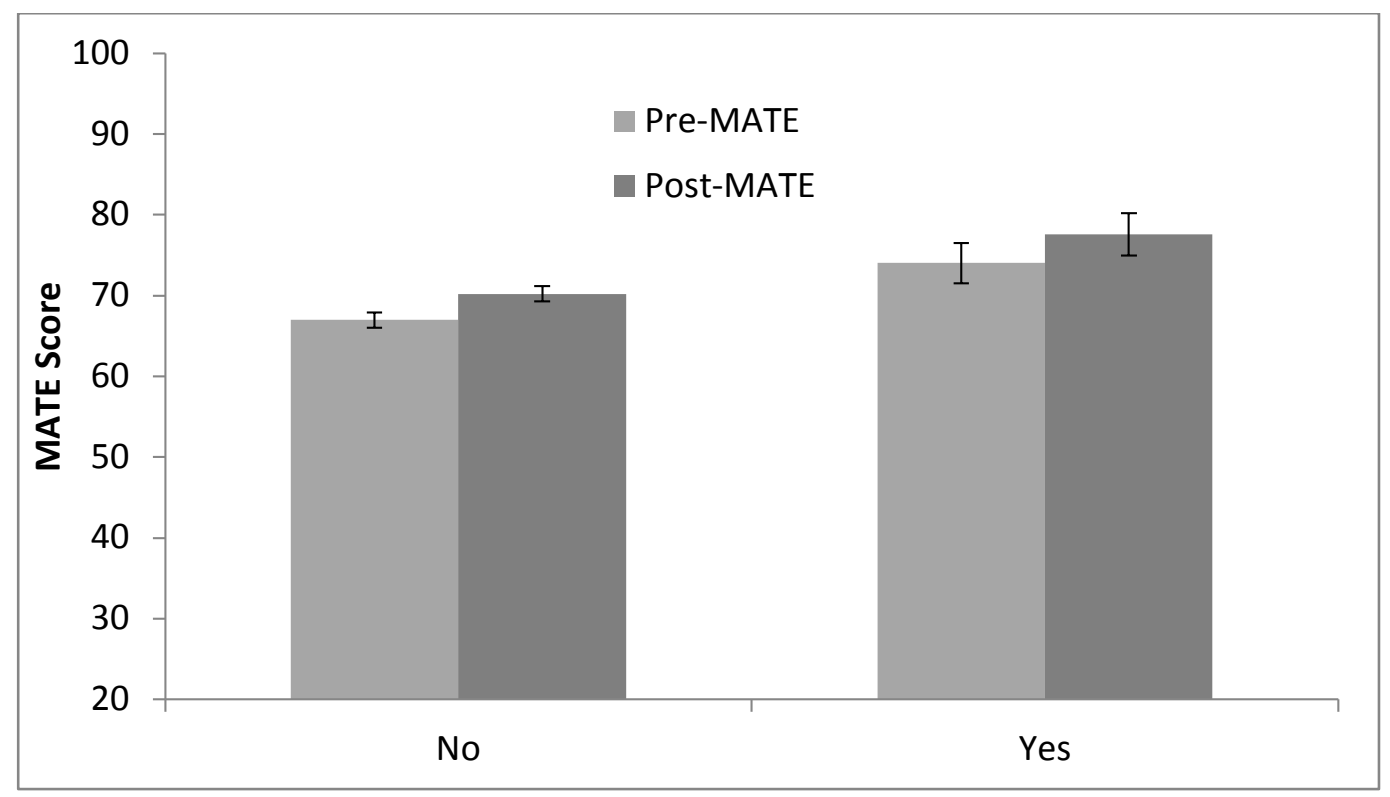

Figure 9A. Average pre-and post-MATE scores for students based on their responses to the query "If a supreme deity exists that is responsible for the existence of the universe, could they also be responsible for evolution, resulting in humans descending from an ancestral primate?" There were significant differences between MATE scores based on student responses. On average, students responding "Yes" scored significantly higher on both the pre and post-MATE $(f(559)=9.40, p<0.01)$ than students who responded "No".

A second such question on the module queried "Could a deity have set in motion physical laws that led indirectly to the form we have today?" There were significant differences between pre and post-MATE scores in both control and experimental groups $(f(479)=4.27, p<0.01)$. Students responding "No" to the query had higher average scores on both the pre and post-MATE than students who answered "Yes". However, students who answered "Yes," experienced significant increases between their pre and post-MATE scores, bringing their post-MATE scores to a comparable level to the pre-MATE scores of the opposing group $(f(479)=4.27, p<0.01)$. 


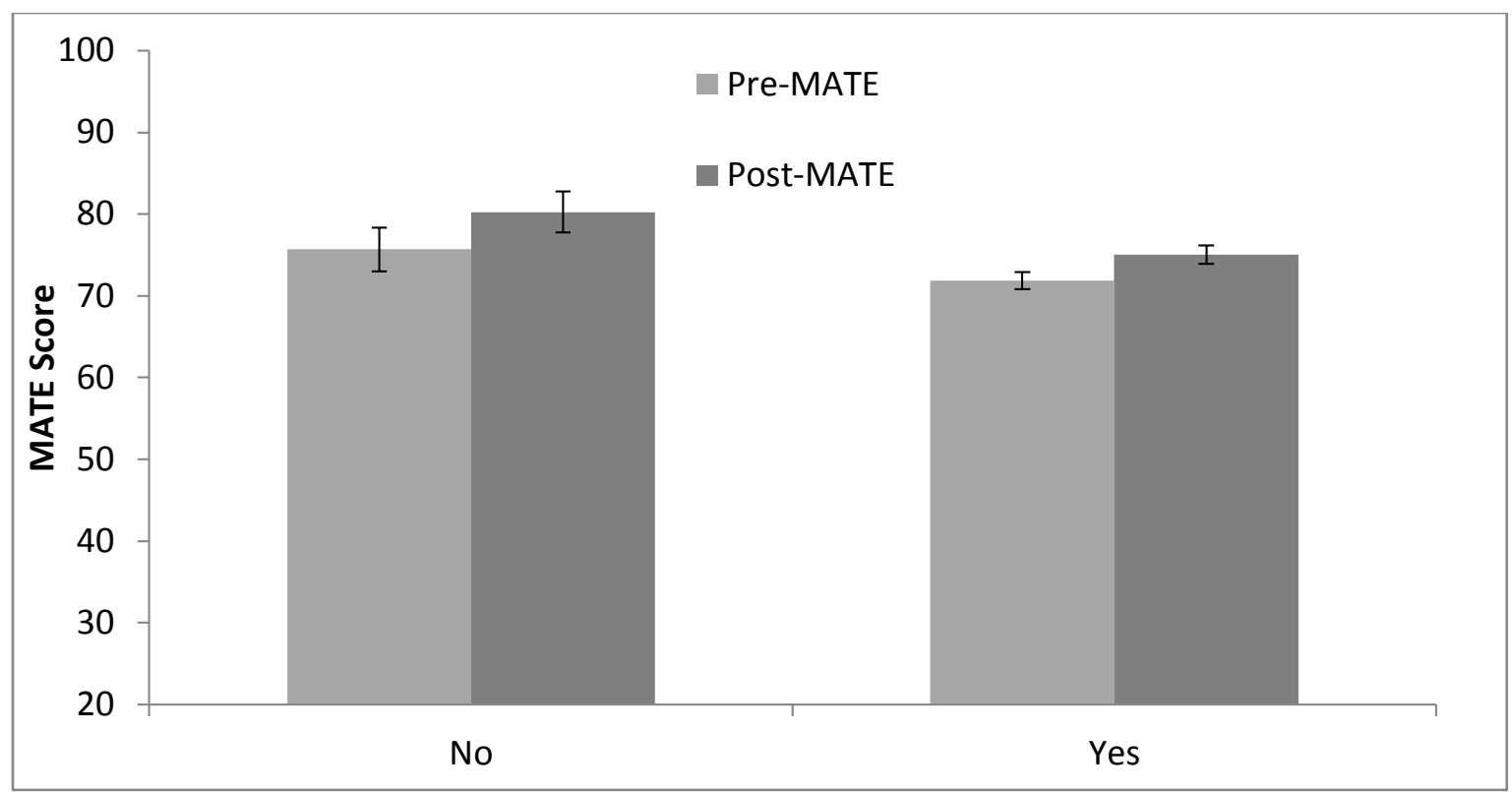

Figure 9B. Average MATE scores for students based on their responses to the query, "Could a deity have set in motion physical laws that led indirectly to the form we have today?" Students responding "No" to the query had higher average scores on both the pre and post-MATE. Students who answered "Yes," experienced significant increases between their pre and post-MATE scores $(f(479)=4.27, p<0.01)$.

The final item on the experimental module asked students to select the statement of personal view toward evolution and religion that they most closely identified with. The following were the possible options to choose from:

- (A) The earth is young (6,000-10,000 years), with each of the six days of Genesis/ Creation being 24-hour days. God created each kind of organism in its present form.

- (B) The earth is ancient (billions of years), with each of the six days of Genesis/ Creation being long periods of time (thousands or millions of years). God created each kind of organism in its present form.

- (C) The earth is ancient (billions of years). Biological evolution occurs, but God has intervened at critical points to produce species as they exist today.

- (D) The earth is ancient (billions of years). Biological evolution describes a natural process that produces species. Biological evolution supports the idea that God exists. 
- (E) The earth is ancient (billions of years). Biological evolution describes a natural process that produces species. Biological evolution neither supports nor denies the existence of God.

- (F) The earth is ancient (billions of years). Biological evolution describes a natural process that produces species. Biological evolution supports the idea that God does not exist

There were significant difference between the average scores on the pre- and post-MATEs for students who were grouped based on their identification with different views of evolution. Average MATE scores increased as responses moved further from a young earth creationist viewpoint $(f(635)=23.90, p<0.01)$. Students who identified as young earth creationists scored lower on both the Pre and Post MATE, and were the only group to actually decrease in average acceptance, though not significantly (figure 10).

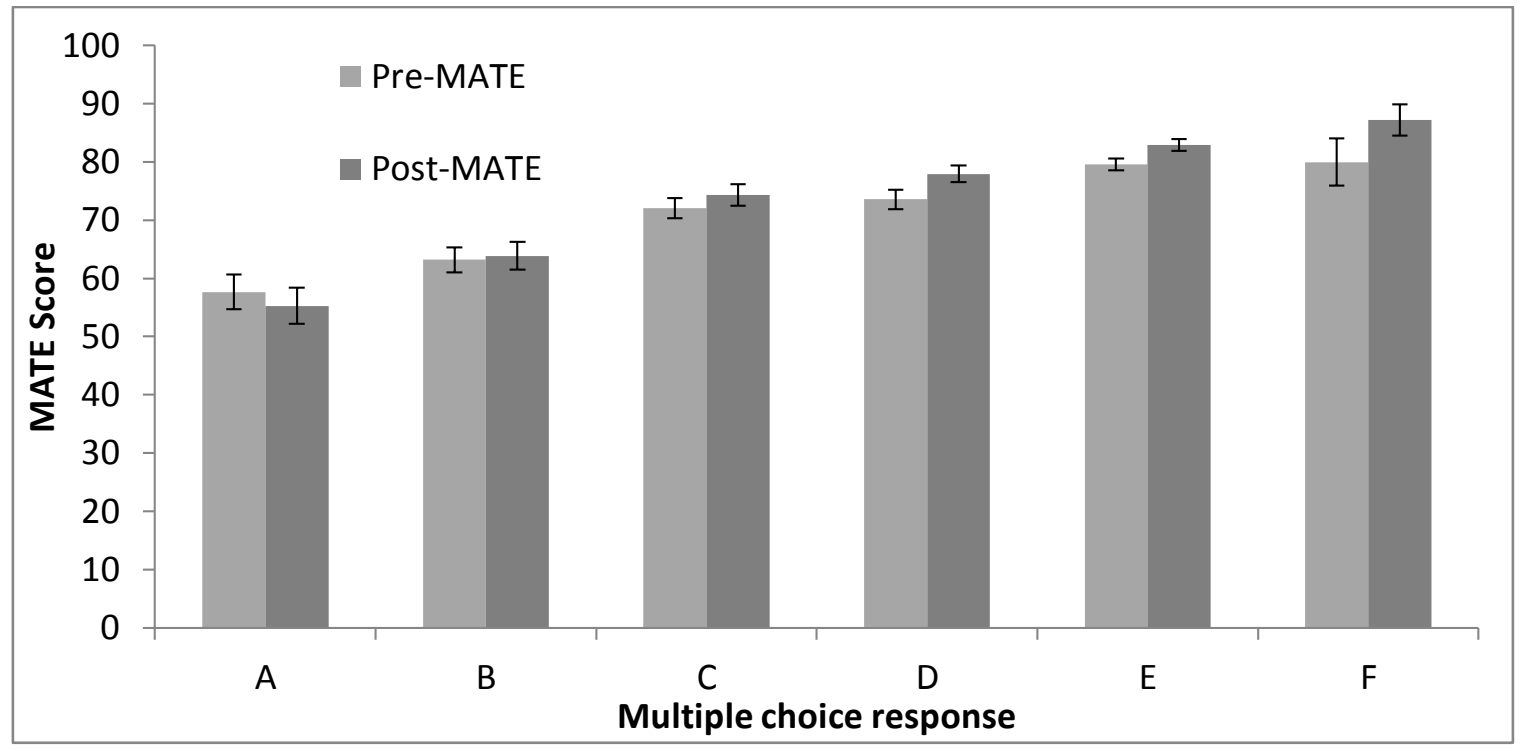

Figure 10. Average MATE scores for students grouped based on their personal views of evolution. Students who selected responses more closely identifying with those of young-earth creationists scored significantly lower on both the pre and post-MATE. In general, as responses moved further from the creationist viewpoint, average scores increased $(f(635)=23.90, p<0.01)$. 


\section{Discussion:}

Given that much of the public (Gallup, 2014), and even many biology majors within the United States do not readily accept evolution, despite the abundant scientific evidence supporting the theory (Verhey, 2005; Moore and Cotner, 2009), it is important to study alternative methods for teaching evolution that directly address resistance to acceptance. Since traditional college biology courses are often focused on presenting scientific evidence for evolution which has been met with limited success in increasing acceptance of the topic (Ingram \& Nelson, 2004), this study aimed to determine the effect of an intervention that fosters self-reflection on personal beliefs.

While previous studies have shown that acceptance among college students is not significantly different from the rest of the public (Woods and Scharmann, 2001), around 60\% of our participants indicated some of level of initial acceptance of evolution. The average score on the pre-MATE was 72 on a scale from 20-100 possible points, suggesting that most students agreed with evolution to some degree before any intervention. In fact, only $18 \%$ scored less than 60 points on the pre-MATE indicating some level of disagreement. This might indicate a real difference in acceptance of evolution between our population of student and those of the former studies or it could be a result of the number or wording of questions used to determine acceptance in the previous studies. Considering that there has been some success with approaches based on presentation of evidence of evolution and the source of evidence that we used for our control had been vetted by focus groups for its palatability for general audiences, it was encouraging to see an increase in acceptance by students using both approaches. This demonstrates that, despite having a moderately high average initial acceptance a brief learning module that takes only 20-30 minutes to complete, can significantly increase acceptance of evolution without utilizing a large amount of class time. Since many instructors indicate concerns with amount of available class time (Silva, 2012), the possibility that student acceptance can be significantly increased in the time 
it takes to complete a short homework assignment could serve as an appealing component of effective education instruction.

Increases in student learning of evolution concepts were not different between the control and experimental groups, but there were significant differences between course sections. The seven sections were taught by five instructors, all but one of whom had training in scientific teaching. One of the four who were trained in scientific teaching had only a year of teaching since completing the summer institute to practice implementation of the techniques. It might be expected that both the experimental and control groups of students would experience similar improvements in conceptual understanding given that they were exposed to similar evolution content in class. Despite no difference existing neither between control and experimental groups nor between course sections on the pre- $\mathrm{Cl}$, there were significant differences in post-Cl scores by course section. Considering the evidence supporting active, student-centered learning tends to be more effective for student learning (Silva, 2012; Knight \& Wood, 2005, Freeman et al., 2014), it is not unreasonable to expect that instructors with many more years of experience implementing scientific teaching would have engaged students more effectively with the concepts of evolution resulting in students who scored higher on the post- $\mathrm{Cl}$. However, when dealing with courses taught by different instructors, there are many possible variables that could affect student learning, and this is just one obvious factor that differs in the same way as the data on student learning.

As with the differences in conceptual gains, the slight differences in pre-MATE scores vary with the instructors' levels of experience with scientific teaching. Since the pre-MATE was not administered until thirteen weeks into the semester, the increased use of active learning to improve student thinking and problem-solving in some sections may have influenced the way that students approached the preMATE questions. Even though the initial difference between sections was small, if the difference in use 
of reformed pedagogies is a/the causative factor, the many initiatives focused on reforming postsecondary STEM education will benefit efforts to improve evolution education. The fact that the modules eliminated the pre-acceptance differences is promising because this short online learning module can increase acceptance without requiring extra class time and regardless of the methods being employed by their instructors. For that reason, this type of approach could be very promising for use in high schools where the training and beliefs of the instructors have a big impact on how evolution is taught and the level of resistance by their students (Rutledge and Mitchell, 2002), Since the differences in pre-MATE scores were small, it would be beneficial to study these effects on a more diverse group of instructors.

When student learning gains were separated based on pre-MATE scores, we found that the experimental module had higher average per-student gains for nearly every group of student, and were even more exaggerated in the groups where initial acceptance was low. Although average MATE gains were not significantly different between groups, this difference in distribution suggests that the experimental approach influences many students more effectively than activities based on the presentation of evidence for evolution. Since the number of students in each group was too small to perform comparative statistics, further research should be performed in order to determine the significance of this relationship. Further emphasizing that the experimental module influenced a different audience than the control module is the fact that there was a significant moderate correlation, between pre-MATE acceptance and acceptance gains in students that initially disagreed with evolution in the experiment group. Due to the complexity of student beliefs and the high variability in student perceptions and susceptibility to change, there are many factors that may influence acceptance of evolution (Silva, 2012). With such a multifaceted issue, even a small correlation is valuable in researching the influences of student acceptance. There was also a trend towards a significantly higher average in acceptance gains among students who had lower levels of initial agreement. Although not 
significant, the trend implies that this group could be particularly impacted by interventions that focus on addressing issues with acceptance rather than just presenting evidence. Further research focusing particularly on this group is needed.

The experimental module was designed to engage students in confronting their own beliefbased barriers to accepting evolution. Patterns in student responses to individual queries in the module were representative of scores on the MATE. When asked, "If a supreme deity exists that is responsible for the existence of the universe, could they also be responsible for evolution, resulting in humans descending from an ancestral primate?" students responding "Yes," had higher average scores on both the pre and post-MATE. This was not unexpected since a response of "No" may imply a more creationist and potentially resistant viewpoint. Although, when asked "Could a deity have set in motion physical laws that led indirectly to the form we have today?" students responding "Yes" scored lower on the pre and post-MATE, but there was a substantial increase in post scores which were comparable to the preMATE scores of those responding with "No." This may indicate that a change in perception occurred in a cohort of students when considering this question. The final question on the experimental module asked students which viewpoint they most closely identified with, and although the relations between responses and MATE scores are not surprising, it is important to note that this was the final question and most changes in perception would likely have occurred prior to this point.

Considering that responses on the experimental module questions were somewhat indicative of MATE scores, it would seem that disagreement with evolution would relate to an increased resistance to learning evolution-based content, so it was surprising to see that there was only a weak relationship between post-survey acceptance (post-MATE) and normalized learning gains on evolution-based topics. This finding is not new and reinforces previous findings where only weak relationships have be determined between acceptance of evolution and course achievement (Ingram \& Nelson, 2005). It is 
possible, however, that participation in intervention may have helped students to be more receptive to learning evolutionary principles. The post-test only included four evolution questions, two per student, which may have affected the richness of the analysis, but the fact that there is a measurable and significant relationship indicates that intervention to acceptance should not be neglected when teaching evolution-based content.

This module was designed and implemented for use prior to formal instruction of evolution occurring in the classroom. According to a previous survey, most instructors of evolution-based courses agree that their courses should be reserved for science and tend not to address outside topics, such as intelligent design and creationism (Wilbur, 2015; unpublished). In accordance with this philosophy, the experimental module was intended for use online as a supplement to standard course material. Since evidence can have an effect on student acceptance, it may be supplemented with material that addresses barriers to acceptance of evolution as homework to prepare students for in-class lessons on evolution. Since this type intervention appears to improve acceptance, regardless of instructional methodology, it may serve as an appropriate primer to in-class instruction that primarily uses evidence to teach evolution. Further development and improvement of interventions like ours could serve to improve student knowledge and acceptance of evolution. 
Chapter IV: Discussion 


\section{Discussion:}

This thesis addresses the current state of evolution education at the post-secondary level in the United States and explores an alternative teaching method to help students overcome barriers to acceptance of evolution. In this section, I will discuss my findings in context of what is known in the field.

Considering the low rate of acceptance of evolution in the United States, understanding how to better teach it is among the most important topics for education-based research. It is a foundational theory in biology and impacts the lives of the public especially with respect to health and climate issues. An evolutionarily literate public can better appreciate some of the threats of climate change, the importance of being appropriately vaccinated, and the consequences of improper antibiotic use. More importantly, acceptance and understanding of the principles of evolution indicate a practical and applicable literacy in science. College instruction, even from the curricula necessary for biology majors, has limited success in increasing acceptance of evolution (Verhey, 2005; Moore and Cotner, 2009).

The history of public rejection of evolution in this country is closely tied to the religious fundamentalist movement in the early $20^{\text {th }}$ century. This movement greatly influenced public perception and nearly extinguished the teaching of evolution in high schools. While federal and statemandated science content standards have been helping to undo this damage, the effect on high school evolution instruction is still clear and public perception of evolution has not undergone much change. The view of the public continues to influences how evolution is taught through policy, advocacy, and pressure on the educational system.

The present state of evolution education in high schools is compounded by a lack of consistent training in evolution and biology for high school teachers. In the absence of a background in 
evolutionary theory, high school instructors succumb to public pressures or their own lack of acceptance and fail to dispel their students' misperceptions thus perpetuating resistance to evolution. Students who continue on to college carry these barriers to evolution with them.

Surprisingly, college biology instruction is largely ineffective at removing student barriers to evolution. The factors that impede effective evolution instruction at the high school level are fairly well understood, however many fewer studies have focused on the college level. Since most college instructors have post-graduate training in their major subject, lack of understanding or acceptance of evolutionary theory are assumed not to be contributing factors as they are in high school. However, to properly diagnose the problem and improve acceptance among college students, we need to first understand the state of evolution education in college classrooms across the United States.

Chapter two of this thesis presents data about the teaching practices and personal views of college instructors of evolution collected from a national survey. This survey demonstrated that generally, instructors of college evolution courses are relatively consistent in the topics that they teach and in their own personal acceptance of evolutionary theory. Most instructors of evolution, regardless of institution type held post-graduate degrees, taught the same core-concepts, used similar instructional resources, accepted biological evolution, and the same views of implementation of alternative explanations to evolution in the classroom.

Despite little variation throughout most of the items on the survey, it was enlightening to see that a few respondents held Creationist viewpoints. Among instructors of evolution-based courses, it was surprising to see any respondents identifying with creationism, even though this is not unusual among high school teachers. Although this was a very small percentage (approximately 2 percent of respondents), there are still a number of students that may be influenced by the teachings of those individuals. There were also a few respondents that claimed that evolution and alternatives such as 
Intelligent Design/ Creationism should both be taught as valid science and a few more that indicated that neither should be taught as science. The exposure to evolution that these instructors have as a background is unclear, so it is difficult to determine what is influencing how the topic may be portrayed in their classes. It was also interesting to see the difference between how instructors felt evolution should be taught in science classes compared to how they actually administer those classes. Almost all respondents indicated that they thought it would be beneficial to address alternatives to evolution as examples of flawed science. Most of the difference between what instructors think should be taught and what they actually teach was attributed to a lack of available time to address non-scientific topics. Considering this restriction, it may be fruitful to examine the effectiveness of addressing the scientific flaws with alternatives such as Creationism, in increasing student acceptance of evolution. Since, performance on course content is loosely related to acceptance (Ingram \& Nelson, 2005) and increases in acceptance are limited in evidence-based courses, it may be more productive to implement alternative topics into courses aimed at improving acceptance.

Addressing the scientific flaws with alternatives to evolution may influence acceptance, but previous research suggests that increased student interaction and engagement, including direct confrontation of misconceptions can also result in significant increases (Grant, 2009; Silva, 2012). Knowing this, it was encouraging that the most common teaching method in evolution-based classes was reported as a mixture of active learning and lecture. Although, this could include a wide range of instructional strategies as well as degree of implementation and the proportion of actual student engagement could not be determined from our study. It would be beneficial to analyze the degree of student-centered interaction that is occurring in evolution classrooms and the range of impacts on acceptance given various degrees of interactive instruction. Many students self-report distrusting the effectiveness of active-classes, despite increased learning (Knight \& Wood, 2005)), so it may be interesting to see if student perception differs based on varying methods of instruction of evolution- 
based content. Since our survey did not distinguish degrees of engagement, it is unknown how interactive evolution education tends to be, but it would be advantageous to know the extent of the influence of active learning on student acceptance. Active learning has been definitively shown to improve student learning (Freeman et al., 2014), so it already seems appropriate to take this approach to teaching evolution, but the extent of its effect on acceptance of evolution is still widely unknown.

The data collected from the survey was effective in establishing a clearer picture of what is happening in college evolution courses throughout the United States (Holbrook et. al. 2005) and will be of value in promoting further research and advocacy for evolution education improvements. This work has shown that, unlike high school teachers, post-secondary instructors do not have a problem with lack of exposure or training in evolutionary biology. Acceptance of evolution among post-secondary instructors is almost unanimous and the teaching of evolution in post-secondary institutions is widespread, and yet college students, and even biology majors, are not significantly more likely to accept evolution than the public. Considering that traditional lecture methods are not very effective at promoting learning even when students do not have pre-existing resistance to a topic, using improved pedagogical techniques to teach all biological concepts will be necessary. This will be especially true for topics like evolution where active efforts by non-science organizations seek to undermine scientific evidence.

The third chapter of this thesis addresses the challenge of finding alternative, effective methods of addressing students' resistance to evolution in the classroom. In order to do this, I investigated the impact of a learning activity that promotes personal reflection on views and beliefs that may be serving as barriers to accepting evolution.

In addition to showing the need for alternative methods for addressing acceptance of evolution in post-secondary courses, the survey data presented in chapter 2 revealed the extensive use of online- 
resources as supplementary teaching materials. While computer-based teaching methods have been increasing in popularity, as they have become more accessible and practical, the current degree of implementation was higher than assumed. Computer-based activities provide unique opportunities for teaching and learning, as well as a vehicle for wide-spread dissemination of information and tools. For topics with the potential for resistance, such as evolution, the anonymity provided by computers offers a method for students to express their views without fear of confrontation. For that reason, we decided that an online intervention to improve evolution acceptance would be the most suitable approach to address the second aim in the thesis. Since it has been shown that evidence has a limited effect on increasing acceptance to evolution (Ingram and Nelson, 2006), we decided to attempt an alternative approach that involved guided self-reflection by students on personal beliefs and misconceptions that could potentially act as barriers to accepting evolution.

Although there was very little variation among instructors of evolution at the post-secondary level, there are distinctions between teachers that cannot be ignored, such as instructional methods used and experience of the instructors. Instructors involved in teaching the introductory biology course through which the learning module was administered had different pedagogical training and different degrees of experience implementing their training, so it was not surprising to see small differences in student acceptance of evolution on the pre-MATE perception survey. Despite these differences, there was difference between instructors on the post-MATE, regardless of which module the students participated in. This suggests that despite differences in teaching methodology and effectiveness, acceptance of evolution can be increased and normalized using a computer-based intervention. This is particularly encouraging, and demonstrates that intervention should be used in a more widespread manner in order to standardize and improve upon teaching of evolution across the United States. The initial difference in acceptance rates between course sections was small, but being able to standardize 
student acceptance could be very helpful when teaching controversial topics so, it would be valuable to pursue further research to determine the extent of the effect of this type of intervention.

A major concern among instructors is the amount of time they have available, which is a common reason for not including discussion of alternative topics to evolution in their classes. Since time is a limiting factor in many classes, it was exciting and valuable that acceptance of evolution could be increased during the course of a module that took only 20-30 minutes to complete. The idea that a brief intervention activity can increase student acceptance in evolution is encouraging since it means that little extra time and effort need to be devoted by instructors in order to decrease resistance in their classes. This decrease in resistance can also manifest in increased time spent on content that may have otherwise been devoted to responding to student concerns.

Based on the knowledge that evidence has a limited effect on influencing acceptance of evolution, it was the assumption of the authors that an intervention designed to confront misconceptions and belief-based barriers could influence students not typically swayed by evidence. Despite there being no difference in average acceptance gains between the evidence-based module and the experimental module, there was a negative relation between students' pre-MATE score and normalized acceptance gains for students initially disagreeing with evolution in the experiment group. Also, when organizing student acceptance gains into groupings based on pre-MATE scores, the experimental module was more effective at increasing gains in nearly all groups, except among those that already had high rates of agreement with evolution. This implies that the experimental approach may be more effective among students who have a lower initial acceptance. Considering that most students fall into the range of "Low-Agreement," it is important not to neglect the potential for change among this population. Although only showing a trend towards significance, the experimental module appeared to have a higher influence among this group than the control module, implying that these 
students could benefit more from non-traditional intervention methods than from evidence. These results suggest that the experimental model affects a different target-audience than the evidence-based model, so when implemented in tandem with an evidence-based approach in the classroom, a broader effect can be obtained than in traditional instruction. This can be important knowledge when determining appropriate forms of intervention for any given level of acceptance. Considering that this approach is new, further experimentation should be performed to determine the extent of this effect.

When students are resistant to accepting evolution, it may seem logical that difficulties learning the content would arise. However, acceptance seems to play only a small role in course performance. There was only a very weak relationship between acceptance of evolution at the start of formal classroom instruction and increase in learning on evolution-based questions. This aligns with previous findings where acceptance of evolution was shown to have a weak impact on performance in class (Ingram \& Nelson, 2006). It is not surprising that there is a relationship, but it seems logical that students would perform better on evolution material if they are not resistant to the topic, so a stronger relationship was expected. Since these findings are not among the primary aims of this, nor previous studies, it would be beneficial to explore the extent of this relationship in more depth.

A brief online learning module can significantly increase student acceptance of evolution without using an extensive amount of class time. While evidence-based interventions can increase student acceptance, a module designed to address student barriers can influence a wider variety of students, specifically those with lower initial acceptance. With the possibility of improving and standardizing acceptance among students, regardless of instruction, the utility of this intervention method extends far beyond post-secondary education and could be very effective among high school teachers who are far more variable in their backgrounds. Implementation of a short learning module designed to confront student misconceptions and belief-based barriers to accepting evolution in tandem 
with teaching the evidence associated with evolution in a classroom shows an understanding and appreciation for a diversity of students and does not direct teaching at only a single group of learners.

The findings of the survey performed for this thesis indicate that there is very little variation among instructors of evolution at the post-secondary level. One area where nearly all college instructors can improve is in the use of scientific teaching and student-centered practices. Since active learning increases student learning in general, it would be beneficial to examine the effect of various degrees of student-centered teaching on acceptance of evolution. Since introspection into personal barriers can improve acceptance of evolution, it can be expected that course content focused on student perceptions could show similar increases that may not be present in less learner-centered environments. 


\section{References Cited:}

Alters, B, Nelson, C. (2002). Perspectives: Teaching Evolution in Higher Education. International Journal of Organic Evolution. 56(10), 1891-1901.

Anderson, C., Kellam, K., (1992). Belief Perseverance, Biased Assimilation, and Covariation Detection: The Effects of Hypothetical Social Theories and New Data. Personality and Social Phychology Bulletin. 18(5), 555-565.

Basic Classification Tables. Carnegie Foundation for the Advancement of Teaching. 2010.

http://carnegieclassifications.iu.edu/descriptions/basic.php

Bishop, B, Anderson C. (1990). Student conceptions of natural selection and its role in evolution. Journal of Research Science Teaching. 27(5), 415-427.

Branch, G., Scott, E. (2009). The latest face of creationism. Scientific American. 300, 92-99. DOI: $10.1038 /$ scientificamerican0109-92

Brem, S., Ranney, M., Schindle, J. (2003). Perceived consequences of evolution: college students perceive negative personal and social impact in evolutionary theory. Science Education. 87, 181-206.

Colburn, A., Henriques, L. (2006). Clergy views on evolution, creationism, science, and religion.Journal of Research in Scientific Teaching. 43, 419-442

Freeman, S., Eddy, S., McDonough, M., Smith, M., Okoroafor, N., Jordt, H., Wenderoth, M. (2014). Active learning increases student performance in science, engineering, and mathematics. Proceedings of the National Academy of Sciences. 111(23), 8410-8415.

Gallup Incorporated. (2006, 2008, 2010, 2012, 2014). www.gallup.com/home.aspx.

Garvin-Doxas \& Klymkowsky. Understanding Randomness and its impact on Student Learning: Lessons from the Biology Concept Inventory (BCI). Life Sciences Education 7. (2008): 227-233.

Grant, B. (2009). Practitioner research improved my students' understanding of evolution by natural selection in an introductory biology course. Teaching Issues and Experiments in Ecology. 6(4). http://tiee.ecoed.net/vol/v6/research/grant/abstract.html.

Gregory, T. (2009). Understanding Natural Selection: Essential Concepts and Common Misconceptions. Evolution: Education and Outreach. 2, 156-175. Doi: 10.1007/s12052-009-0128-1

Heddy, B., Nadelson, L. (2012). A global perspective of the variables associated with acceptance of evolution. Evolution Education and Outreach; 5(3). DOI: 10.1007/s12052-012-0423-0 
Holbrook, A, Krosnick, J, Pfent, A. (2005). The Causes and Consequences of Response Rates in Surveys by the News Media and Government Contractor Survey Research Firms. In Advances in Telephone Survey Methodology (499-590). John Wiley \& Sons, Inc.

Ingram, E, Nelson, C. (2006). Relationship between achievement and students' acceptance of evolution or creation in an upper-level evolution course. Journal of Research in Science Teaching. 3(1), 724

Klayman, J. (1995). Varieties of confirmation bias. Psychology of Learning and Motivation. 32, 385-418.

Knight, J., Wood, W. (2005). Teaching more by lecturing less. Cell Biology Education. 4, 298- 310.

Köse, E. (2010). Biology students' and teachers' religious beliefs and attitudes towards theory of evolution. H.U. Journal of Education. 38, 189-200.

Martin, B, Brouwer, W. (1991). The sharing pf personal science and the narrative element in science education. Science Education. 75(6), 707-722.

Meade, A, Craig, S. (2011). Identifying careless responses in survey data. Paper presented at the $26^{\text {th }}$ Annual Meeting of the Society for Industrial and Organizational Psychology, Chicago, IL.

Miller, J, Scott, E, Okamoto, S. (2006). Public Acceptance of Evolution. Science. 313, 765-766.

Moore, R. (2001). The lingering impact of the Scopes trial on high-school biology textbooks. Bioscience. 51(9) 790-796.

Moore, R, Cotner, S. (2009). The creationist down the hall: does it matter when teachers teach creationism? Bioscience. 59(5), 429-435.

Nelson, C. (2008). Teaching evolution (and all of biology) more effectively: Strategies for engagement, critical reasoning, and confronting misconceptions. Integrative and Comparative Biology. 48(2): 213-212

Palumbi, S. 2001. Humans as the world's greatest evolutionary force. Science. 293(5536): 1786- 1790.

Pennock, R. (2003). Creationism and intelligent design. Annual Review of Genomics and Human Genetics. 4, 143-163. DOI 10.1146/annurev.genom.4.070802.110400

Rice, J, Olson, J, Colbert, J. (2010). University Evolution Education: The Effect of Evolution Instruction on Biology Majors' Content Knowledge, Attitude Toward Evolution, and Theistic Position. Evolution: Education and Outreach. DOI 10.1007/s12052-010-0289-y

Rutledge, M, Mitchell, M. (2002). High School Biology Teachers' Knowledge Structure, Acceptance \& Teaching of Evolution. The American Biology Teacher. 64(1):21-28 
Rutledge, M, Warden, M. (1999). The Development and Validation of the Measure of Acceptance of the Theory of Evolution Instrument. School Science and Mathematics. 99(1), 13-18.

Rutledge, M., Warden, M. (2000). Evolutionary theory, the nature of science \& high school biology teachers: critical relationships. The American Biology Teacher. 62(1), 23-31.

National Academy of Sciences and Institute of Medicine (2008). Science, Evolution, and Creationism. Washington, D.C.: The National Academies Press.

Shi, J., Wood, W., Martin, J., Guild, N., Vicens, Q., and Knight, J. (2010). A diagnostic assessment for introductory molecular and cell biology. CBE-Life Sciences Education. 9(4), 453-461.

Silva, K. (2012). Evolution-centered teaching of biology. Annual Review of Genomics and Human Genetics. 13, 363-380. DOI 10.1146/annurev-genom-090711-163749

Smith, M. (2010) Current status of research in teaching and learning evolution: II. Pedagogical issues. Science \& Education. 19, 539-571.

Smith, M., Wood, W., and Knight, J (2008). The Genetics Concept Assessment: a new concept inventory for gauging student understanding of genetics. Cell Biology Education: Life Science Education. 7(4) 422-30.

Verhey S. (2005). The effect of engaging prior learning on student attitudes toward creationism and evolution. Bioscience. 55(11), 996-1003.

Woods, C., Scharmann, L. (2001). High school students' perception of evolutionary biology. Electronic Journal of Science Education. 6(2).

Zimmerman, M. (2004) The Clergy Letter Project. http://www.theclergyletterproject.org/ 


\section{Appendix A: Survey of Post-Secondary Instructors of Evolution}

\section{Page 1}

Thank you for taking the time to complete this survey. The purpose of this study is to determine how much variation exists in the instruction of evolution at the postsecondary level.

The first part of the survey contains general questions about your institution/department while the remaining questions are about specific evolution courses that you teach. If you teach more than one course where evolution is a primary topic, there are pages available for each course that you instruct.

1. NOTE: This question will NOT be used to track respondents or link responses to any institution. This information will be used solely to prevent overrepresentation of general demographic information from institutions with more than one respondent.

Name of your institution:

2. My institution has the following classification (pick the closest match):

Research University (Masters and Doctoral granting, 4 yr)

Baccalaureate College (May include Masters degrees, 4 yr)

Community or Technical College (2 yr)

Tribal College

Other (please specify)

3. My institution has a religious affiliation:

No

Yes briefly describe

Page 2

4. To the best of my knowledge my institution addresses biological evolution as a major topic of discussion in the following departments (select all that apply):

Agriculture

Astronomy

Chemistry

Education

Ethics

Geology

Mathematics

Medicine

Philosophy

Physics

Political Science

Religion

Other (please specify) 
5. My Biology Department has approximately the following number undergraduate majors.

6. My biology department has a course or courses where (select all that apply):

Evolution is the primary subject of one or more courses.

Evolution is a major subject in one or more courses.

Evolution is incorporated as a minor unit in one or more courses.

Evolution is not addressed in any course.

Other

Page 3

1. My institution has a course[s] on evolution (either primary subject or major unit) for the following (select all that apply):

Biology or Science Majors

Nonmajors

Freshman

Sophmores

Juniors

Seniors

Other (please specify)

2. How often are the evolution courses (primary subject or major unit) offered?

Every quarter

Every semester

Every year

Every other year

Other (please specify)

3. Select the following statement[s] that describe you (select all that apply).

I teach a course where evolution is the primary subject of a course.

I teach a course where evolution is incorporated as a major unit in a course.

I teach a course where evolution is incorporated as a minor unit in a course.

I do not teach a course where evolution is the primary subject or incorporated as a major/minor unit in a course.

\section{Page 4}

If you teach more than one course where evolution is the primary subject or a major unit, the last question on this page will allow you to select another page for that course.

1. The name of the course I teach where evolution is the primary subject or a major unit is (e.g. Biol 100 Introductory biology for Majors)

2. This course serves primarily (select all that apply): 
Freshman

Sophmore

Junior

Senior

Graduates

3. The typical enrollment for this course is:

4. I use the following for this course (select all that apply)

Textbook

Primary literature

Secondary literature

Online resources

Other, please specify

5. If you use a textbook, please provide the title and last name of first author.

\section{Page 5}

6. To what extent are the following topics covered this course?

Science as a Way of Knowing

Evidence/Validation of a Claim

History of Evolutionary Theory

Life of Charles Darwin

Molecular/Mendelian Genetics

Lines of Evidence for Evolution

Mechanism of Natural Selection

Mutations/Source of Variation

Population Genetics

Adaptation

Intraspecific Variation

Speciation

Sexual Selection

Macroevolution

Phylogenetics/Systematics/Classification

Organism Classification

Rates of Evolution

History of Earth

Coevolution

Extinction

7. Please list any additional evolution related topics you address as major units or points of discussion in this course:

8. I use the following as my primary means of instruction. 
Lecturing

Active Learning (e.g. collaborative learning groups, case based learning, project based learning...)

Mixture of lecture and active learning

Other (please specify)

Other

Page 6

9. I use the following forms of assessment in this course (select all that apply).

Examinations with primarily multiple choice

Examinations with a mixture of question types (multiple choice, short answer, essay...)

Term papers

Projects

Presentations

Other (please specify)

10. There is a lab associated with the evolution portion of this course:

Yes

No

No, but there are plans to implement one in the future

There was a lab in the past, but this portion of the course is no longer present

11. Briefly describe the evolution portion of the lab associated with this course.

12. I teach another course where evolution is a major topic and need an additional page to describe it:

True

False

Course Description Page Repeats for those responding True to Question 12

Page 16

1. The highest degree I have attained is:

Associates

Bachelors

Masters

PhD

Other (please specify)

2. My highest degree was obtained in the following discipline:

3. In the U.S. today there is a great deal of public debate over the teaching of biological evolution in public science classes. Other ideas, such as intelligent design/creationism, have been put forth as alternatives. 
Please give us your thoughts on including alternative ideas in your classroom. If you include discussion of alternative ideas such as intelligent design in your course, please briefly describe why and how? If you do not include discussion of alternative ideas, please explain.

4. Given the public debate over how evolution is taught, please rate your level of agreement with the following statements about how college science courses SHOULD be taught.

Only biological evolution should be taught in college science classes

Only intelligent design/creationism should be taught in college science classes

Both should be taught as valid scientific ideas

Only biological evolution should be taught as a valid scientific idea, but intelligent design/creationism might be addressed to educate students about the nature of science and why intelligent design/creationism is not accepted by the scientific community

Neither should be taught as valid scientific ideas

I don't know enough about the subject to make a choice

Page 17

5. Please rate your level of agreement with the following statements about how YOUR college science courses ARE TAUGHT.

Only biological evolution is taught in my college science classes

Only intelligent design/creationism is taught in my college science classes

Both are taught as valid scientific ideas in my college science classes

Only biological evolution is taught as a valid scientific idea in my college science classes, but intelligent design/creationism is addressed to educate students about the nature of science and why intelligent design/creationism is not accepted by the scientific community Neither are taught as valid scientific ideas in my college science classes

6. My answers to the previous two questions regarding how evolution SHOULD be taught and IS TAUGHT in my courses were the same:

Yes

No (please explain)

7. My school requires me to

teach alternatives such as Intelligent Design/Creationism in evolution classes.

avoid teaching alternatives such as Intelligent Design/Creationism in evolution classes.

Neither

I don't know if my school has a requirement for the way evolution is taught.

Page 18

8. Please read all of the following options, then select the one that is CLOSEST to your perspective. 
The earth is young (6,000-10,000 years), with each of the six days of Genesis/ Creation being 24 hour days. God created each kind of organism in its present form.

The earth is ancient (billions of years), with each of the six days of Genesis/ Creation being long periods of time (thousands or millions of years). God created each kind of organism in its present form.

The earth is ancient (billions of years). Biological evolution occurs, but God has intervened at critical points to produce species as they exist today.

The earth is ancient (billions of years). Biological evolution describes a natural process that produces species. Biological evolution supports the idea that God exists.

The earth is ancient (billions of years). Biological evolution describes a natural process that produces species. Biological evolution neither supports nor denies the existence of God.

The earth is ancient (billions of years). Biological evolution describes a natural process that produces species. Biological evolution supports the idea that God does not exist.

None of these options fit my perspective. If you select this answer, please describe your perspective in the following text box

9. In my view, the theory of evolution explains (rate your agreement for the following choices):

the origin of life on earth

the diversity of species

the origin of humans

Page 19 - Those responding that no courses currently include evolution as a major or primary unit of instruction.

1. Are there any plans to implement a course addressing evolution in the future?

Yes

No

Unknown

2. My institution has a course addressing Intelligent Design/ Creationism (select all that apply):

Yes, this course is taught as/in a science class

Yes, this course is taught as/in a religion class

Yes, this course is taught as/in a philosophy class

Yes, this course is taught as/in a social science class

No

I don't know

Page 20

Thank you for taking time to complete this survey. 


\section{Appendix B: Evolution Experimental Learning Module}

Please read all instructions and answer questions accordingly. During the module you will be given a brief reading along with some short answer questions. Please read the questions and consider your response in a logical and thoughtful manner. Answer each question thoroughly and completely.

All responses will be kept as anonymous as possible and will not affect your standing in class or at WVU in any way.

Please read the following as part of the learning module. You will be asked questions related to the reading.

Even though there is more evidence to support and explain the mechanisms of evolution than the theory of gravity, many people still have trouble accepting the theory of evolution. From psychology research, we know that as humans, we tend to stick to what we already believe, even in the face of information that contradicts those beliefs, and we tend to filter incoming information to selectively "hear" only things that support our beliefs. Conflict of interest can also shape our beliefs or how we respond to new information. For example, a person who smokes cigarettes and doesn't wish to quit will be more likely to dismiss evidence relating smoking to an increased risk of cancer or cardiovascular disease. For whatever reason, people in the U.S. tend to feel more conflict of interest between believing in a supreme deity and accepting evolution. Thousands of religious leaders and practitioners, from a variety of religions (Christianity/Catholicism, Judaism, Buddhism), have signed the Clergy Letter Project (http://www.theclergyletterproject.org/) showing their support for the theory of evolution and the lack of conflict between acceptance of evolution and belief in a deity. The following quote from the Clergy Letter Project exemplifies the goal of this project:

- "For too long, the misperception that science and religion are inevitably in conflict has created unnecessary division and confusion, especially concerning the teaching of evolution. I wanted to let the public know that numerous clergy from most denominations have tremendous respect for evolutionary theory and have embraced it as a core component of human knowledge, fully harmonious with religious faith."

Unfortunately, many people are still unaware that evolutionary theory is supported by clergy from many religions. To help remedy this, we wanted to create a short web-based activity to make students aware of this and help them reflect on their own beliefs and potential conflicts with the hope of removing barriers to a clearer understanding of evolution.

During the 1500/1600s, based on the movements of heavenly bodies, Copernicus and Galileo put forth the idea that the Earth revolved around the sun, not the other way around. As a result, Galileo was imprisoned for heresy because the Catholic Church held the belief that Earth's central position in the universe (geocentrism, i.e. the sun, and everything else in the universe revolves around earth) was an indication of humanity's central position as God's creation. Therefore, evidence that disputed geocentrism was equated to evidence against the existence of God. While the vast majority of people on the planet are now aware that we revolve around the sun, this information is unlikely to impact their belief in a supreme being. However, many people seem to respond to the evidence that humans have evolved from primates in much the same way. Are people today arbitrarily equating being evolved from 
primates with evidence against the existence of a god, just as the Catholic Church did with heliocentrism (the theory that Earth revolves around the Sun)?

\section{Question 1:}

In Galileo's time, regarding the earth as the center of the universe was strongly associated with the belief that a supreme deity created humanity, making people less likely to accept scientific evidence about the position and movement of the planets and stars. Today, belief in a deity makes people less likely to accept evidence that humans evolved from an ancestral primate. Why could being evolved from an ancestral primate be perceived as less "special", i.e. deserving of being the result of the actions of a supreme being, than being created in the form we are now?

\section{Question 2:}

Could a deity have set in motion physical laws that led indirectly to the form we have today?

\section{Question 3:}

If a supreme deity exists that is responsible for the existence of the universe, could they also be responsible for evolution, resulting in humans descending from an ancestral primate?

\section{Question 4:}

A basic tenet of evolution is that living things change over time driven, in part, by changes in their environment. Human beings can create non-living things that are adaptable, i.e. can change over time or in difference situations. If humans can create adaptable things, why couldn't or wouldn't a supreme deity?

\section{Question 5:}

If there is a supreme being who used evolution to give rise to the amazing diversity of living organisms on earth, then dismissing the evidence for evolution or denying that evolution exists could be denying one of the greatest accomplishments of that deity. Have you ever considered this possibility before? Explain.

\section{Question 6:}

How, if at all, does this perspective affect your stance on acceptance of evolution?

\section{Question 7:}

Please read all of the following options, then select the one that is CLOSEST to your perspective:

A) The earth is young (6,000-10,000 years), with each of the six days of Genesis/ Creation being 24-hour days. God created each kind of organism in its present form. 
B) The earth is ancient (billions of years), with each of the six days of Genesis/ Creation being long periods of time (thousands or millions of years). God created each kind of organism in its present form.

C) The earth is ancient (billions of years). Biological evolution occurs, but God has intervened at critical points to produce species as they exist today.

D) The earth is ancient (billions of years). Biological evolution describes a natural process that produces species. Biological evolution supports the idea that God exists.

E) The earth is ancient (billions of years). Biological evolution describes a natural process that produces species. Biological evolution neither supports nor denies the existence of God.

F) The earth is ancient (billions of years). Biological evolution describes a natural process that produces species. Biological evolution supports the idea that God does not exist.

G) None of these options fit my perspective. 


\section{Appendix C. Control Evolution Learning Module}

Please read all instructions and answer questions accordingly. During the module you will be given a brief reading along with a few questions pertaining to the reading. Please read the questions and answer according to information provided within the reading.

All responses will be kept as anonymous as possible and will not affect your standing in class or at WVU in any way.

All information presented is from the following source:

National Academy of Sciences and Institute of Medicine (2008). Science, Evolution, and Creationism. Washington, D.C.: The National Academies Press

Evolution in Medicine

In late 2002 several hundred people in China came down with a severe form of pneumonia caused by an unknown infectious agent. Dubbed "severe acute respiratory syndrome," or SARS, the disease soon spread to Vietnam, Hong Kong, and Canada and led to hundreds of deaths. In March 2003 a team of researchers at the University of California, San Francisco, received samples of a virus isolated from the tissues of a SARS patient. Using a new technology known as a DNA microarray, within 24 hours the researchers had identified the virus as a previously unknown member of a particular family of viruses a result confirmed by other researchers using different techniques. Immediately, work began on a blood test to identify people with the disease (so they could be quarantined), on treatments for the disease, and on vaccines to prevent infection with the virus. An understanding of evolution was essential in the identification of the SARS virus. The genetic material in the virus was similar to that of other viruses because it had evolved from the same ancestor virus. Furthermore, knowledge of the evolutionary history of the SARS virus gave scientists important information about the disease, such as how it is spread. Knowing the evolutionary origins of human pathogens will be critical in the future as existing infectious agents evolve into new and more dangerous forms.

\section{Evolution in Agriculture}

When humans understand a phenomenon that occurs in nature, they often gain increased control over it or can adapt it to new uses. The domestication of wheat is a good example. By recovering seeds from different archaeological sites and noticing changes in their characteristics over the centuries, scientists have hypothesized how wheat was altered by humans over time. About 11,000 years ago, people in the Middle East began growing plants for food rather than relying entirely on the wild plants and animals they could gather or hunt. These early farmers began saving seeds from plants with particularly 
favorable traits and planting those seeds in the next growing season. Through this process of "artificial selection," they created a variety of crops with characteristics particularly suited for agriculture. For example, farmers over many generations modified the traits of wild wheat so that seeds remained on the plant when ripe and could easily be separated from their hulls. Over the next few millennia, people around the world used similar processes of evolutionary change to transform many other wild plants and animals into the crops and domesticated animals we rely on today. In recent years, plant scientists have begun making hybrids of wheat with some of their wild relatives from the Middle East and elsewhere. Using these hybrids, they have bred wheat varieties that are increasingly resistant to droughts, heat, and pests. Most recently, molecular biologists have been identifying the genes in the DNA of plants that are responsible for their advantageous traits so that these genes can be incorporated into other crops. These advances rely on an understanding of evolution to analyze the relationships among plants and to search for the traits that can be used to improve crops.

\section{Evolution in Industry}

The concept of natural selection has been applied in many fields outside biology. For example, chemists have applied principles of natural selection to develop new molecules with specific functions. First they create variants of an existing molecule using chemical techniques. They then test the variants for the desired function. The variants that do the best job are used to generate new variants. Repeated rounds of this selection process result in molecules that have a greatly enhanced ability to perform a given task. This technique has been used to create new enzymes that can convert cornstalks and other agricultural wastes into ethanol with increased efficiency.

\section{Is Evolution Theory or Fact?}

It is both. But that answer requires looking more deeply at the meanings of the words "theory" and "fact."

In everyday usage, "theory" often refers to a hunch or a speculation. When people say, "I have a theory about why that happened," they are often drawing a conclusion based on fragmentary or inconclusive evidence. The formal scientific definition of theory is quite different from the everyday meaning of the word. It refers to a comprehensive explanation of some aspect of nature that is supported by a vast body of evidence.

Many scientific theories are so well established that no new evidence is likely to alter them substantially. For example, no new evidence will demonstrate that the Earth does not orbit around the Sun (heliocentric theory), or that living things are not made of cells (cell theory), that matter is not composed of atoms, or that the surface of the Earth is not divided into solid plates that have moved over geological timescales (the theory of plate tectonics).

Like these other foundational scientific theories, the theory of evolution is supported by so many observations and confirming experiments that scientists are confident that the basic components of the theory will not be overturned by new evidence. However, like all scientific theories, the theory of 
evolution is subject to continuing refinement as new areas of science emerge or as new technologies enable observations and experiments that were not possible previously. One of the most useful properties of scientific theories is that they can be used to make predictions about natural events or phenomena that have not yet been observed. For example, the theory of gravitation predicted the behavior of objects on the Moon and other planets long before the activities of spacecraft and astronauts confirmed them. The evolutionary biologists who discovered Tiktaalik predicted that they would find fossils intermediate between fish and limbed terrestrial animals in sediments that were about 375 million years old. Their discovery confirmed the prediction made on the basis of evolutionary theory. In turn, confirmation of a prediction increases confidence in that theory. In science, a "fact" typically refers to an observation, measurement, or other form of evidence that can be expected to occur the same way under similar circumstances. However, scientists also use the term "fact" to refer to a scientific explanation that has been tested and confirmed so many times that there is no longer a compelling reason to keep testing it or looking for additional examples. In that respect, the past and continuing occurrence of evolution is a scientific fact. Because the evidence supporting it is so strong, scientists no longer question whether biological evolution has occurred and is continuing to occur. Instead, they investigate the mechanisms of evolution, how rapidly evolution can take place, and related questions.

Please answer the following questions based on information presented in the readings.

Question 1:

A treatment for the SARS virus was able to be discovered due to:

A) the effectiveness and adaptability of the human immune system

B) selected information already known about an evolutionary relative of the virus

C) traditional treatments for other respiratory diseases

D) mapping of the viral DNA and exploiting specific genes

\section{Question 2:}

Humans have been artificially selecting favorable traits in agricultural plants for thousands of years. A modernization of this practice can be seen with:

A) rotating crop fields to produce higher yields.

B) spraying the plants with pesticides to protect them from predation.

C) implementing fertilization techniques. 
D) selected creating hybrids of plants that are better suited to handling adverse conditions

\section{Question 3:}

Fields outside of biology apply evolutionary principles to their work. The reading discussed an example of this when

A) astrophysicists analyze the spectrum of chemicals found in exoplanets in attempts to find components needed for life.

B) selected chemists create, alter and select molecules that function most closely to the desired goal, eliminating those that do not perform adequately.

C) computer programmers use models designed by chemists to create simulations of reactions in order to determine the effectiveness of newly designed molecules.

D) anthropologists study the remains of ancient humans in order to determine information concerning their culture and behaviors. 